\title{
Variable-resolution building exposure modelling for earthquake and tsunami scenario-based risk assessment. An application case in Lima, Peru
}

Juan Camilo Gomez-Zapata, ${ }^{1,2}$, Nils Brinckmann ${ }^{3}$, Sven Harig ${ }^{4}$, Raquel Zafrir ${ }^{1,5}$, Massimiliano Pittore ${ }^{1,6}$, 5 Fabrice Cotton ${ }^{1,2}$, Andrey Babeyko ${ }^{7}$

${ }^{1}$ Seismic Hazard and Risk Dynamics, GFZ German Research Centre for Geosciences, Potsdam, 14473, Germany

${ }^{2}$ Institute for Geosciences, University of Potsdam, Potsdam, 14469, Germany

${ }^{3}$ eScience Centre, GFZ German Research Centre for Geosciences, 14473, Potsdam, Germany

${ }^{4}$ Alfred Wegener Institute, Helmholtz Centre for Polar and Marine Research (AWI), Bremerhaven, 27570, Germany

$10 \quad{ }^{5}$ Head Aerospace Group, Paris, 92250, France

${ }^{6}$ Institute for Earth Observation, EURAC Research, 39100, Bolzano, Italy

${ }^{7}$ Geodynamic Modelling, GFZ German Research Centre for Geosciences, 14473, Potsdam, Germany

Correspondence to: Juan Camilo Gomez-Zapata (jcgomez@gfz-potsdam.de)

Abstract. We propose the use of variable resolution boundaries based on Central Voronoi Tessellations (CVT) to spatially aggregate building exposure models for risk assessment to various natural hazards. Such a framework is especially beneficial when the spatial distribution of the considered hazards present intensity measures with contrasting footprints and spatial correlations such as in coastal environments. This proposal avoids the incorrect assumption that a single intensity value from hazards with low spatial correlation (e.g. tsunami) are considered as representative within large sized geocells for physical vulnerability assessment, without, at the same time, increasing the complexity of the overall model. We present decoupled earthquake and tsunami scenariobased risk estimates for the residential building stock of Lima (Peru). We observe that earthquake loss models for far-field subduction sources are practically insensitive to the exposure resolution. Conversely, tsunami loss models and associated uncertainties depend on the spatial correlations of the hazard intensities as well as on the resolution of the exposure models. We observe that for the portfolio located in the coastal area exposed to both perils in Lima, the ground-shaking dominates the losses for lower magnitudes whilst the tsunami does for the larger ones. For the latter, two sets of existing empirical flow-depth fragility models are used, finding large differences in the losses. This study arise awareness about the uncertainties in the selection of fragility models and aggregations entities for exposure modelling and loss mapping.

\section{Introduction}

The spatial distribution of damage and/or losses expected to be incurred by an extensive building portfolio from a natural hazardous event can be quantified and mapped once a physical vulnerability analysis is performed. For such a purpose, a set of fragility functions per building class is conventionally used. Fragility functions describe the probability of exceeding a certain damage limit state for a given intensity measure (IM) associated with natural hazards, such as spectral acceleration at the yield period (e.g. Fäh et al., 2001) for earthquakes, or tsunami inundation height for tsunamis (Koshimura et al., 2009). These vulnerability calculations are performed at the centroid of every aggregation area of the building exposure model with certain bias (Bazzurro and Luco, 2005), or over weighted points (e.g. Weatherill et al., 2015; Kappos et al., 2008). These aggregation entities can be very diverse, 
35 ranging from administrative units such as district/ communes (e.g. Dunand and Gueguen, 2012); urban blocks (e.g. Papathoma and Dominey-Howes, 2003; Kappos et al., 2008; Figueiredo et al., 2018; Kohrangi et al., 2021); regular grids (e.g. Erdik and Fahjan, 2008; Figueiredo and Martina, 2016) or variable-resolution CVT (Central Voronoi Tessellation) geocells (Pittore et al., 2020). Throughout the physical vulnerability assessment, it is implicitly assumed that the intensity observed or estimated at that location (i.e. centroid or weighted points) is representative for the entire aggregation area. Depending on the considered hazard footprint

40 and IM attenuation, this assumption might not be longer valid if the aggregation area is too coarse compared to the correlation length of a highly varying IM. Besides the aggregation of the building exposure itself, the importance of these geographical entities in natural hazard risk assessment is that they are ultimately used to calculate and map the expected damage and loss metrics (e.g. building replacement/repair costs, human casualties). The diverse types of visualisation and interpretations of this kind of geospatial data define the so-called thematic uncertainties (Smith Mason et al., 2017) that can largely impact further decision making processes (Viard et al., 2011). It is then important to find a compromise between the intrinsic resolution of the hazard IM, on one hand, and the cartographic representation of the exposure models and risk metrics on the other hand.

When a geographically distributed hazard intensity measure IM presents no significant spatial variability within distances of the order of tens of kilometres, they are said to be highly spatially correlated (e.g. Gill and Malamud, 2014; Merz et al., 2020). This is the case of hazards with relatively low attenuation and wide-spread footprints such as ash-falls and earthquakes (de Ruiter

50 et al., 2021). For the latter case, when seismic site conditions (e.g. soil amplification) and path effects (e.g. seismic directivity) are insignificant, seismic ground motion correlation lengths between $10 \mathrm{~km}$ and $25 \mathrm{~km}$ are typical (e.g. Esposito and Iervolino, 2012; Schiappapietra and Douglas, 2020). On the other hand, hazards are called low-spatial correlated if their IM are highly prone to be modified by specific features of the propagation medium. For instance, the modelling of inland IMs from a tsunami (i.e. inundation depth, flow velocity, momentum flux) are highly dependent to be modified by the resolution of the bathymetry and digital elevation models (e.g. Tang et al., 2009); coastal topography (e.g. Goda et al., 2015); coastal morphology (e.g. Song and Goda, 2019), and even built-up areas that heavily interact and modify the inundation footprint and flow velocities (e.g. Kaiser et al., 2011; Lynett, 2016). Moreover, the maximum tsunami IMs also depend on the properties of the triggering earthquake such as its magnitude (e.g. Goda et al., 2014), slip distribution (Miyashita et al., 2020), and directivity of energy radiation (e.g. Kajiura, 1972). Thus, the spatial correlation of inland IMs from tsunamis is very low and remarkably non-linear compared to a much more uniform and

60 highly spatially correlated seismic ground motion. Efforts to visualize uncertainties in the tsunami hazard and risk mapping addressing some of the aforementioned modifiers have been reported in few previous studies (e.g. Goda and Song, 2016; Goda et al., 2020).

Usually, the resolution of exposure models is constrained independently of the hazard, and to a certain extent, also independently of the exposure distribution. That might lead to very poor exposure resolutions where it really matters, i.e. in areas where buildings are densely distributed and/or hazard intensities highly vary with short distances. Or, in contrast, to the unnecessary computation demands for loss assessment in areas with few exposed assets. If aggregation areas of the exposure model are coarser by resolution than the typical correlation lengths of low spatially correlated hazard intensities, then local variations of these intensities would remain hidden in the vulnerability analysis, propagating the associated uncertainties up to the loss estimates. This dependency between exposure resolution and spatial correlation of hazard intensities has been usually disregarded. Some examples of these practices can be found in soil liquefaction risk. Despite the hazard component can be successfully downscaled (e.g. Bozzoni et al., 2020), thematic uncertainties related to visualisation and interpretation of risk metrics can arise if they are mapped over larger regional administrative units (e.g. Yilmaz et al., 2021) instead of being represented at more hazard-compliant resolutions (e.g. Bozzoni et al., 2021). Similarly, despite that the building exposure models for flood and earthquake vulnerabilities can be aggregated at moderate resolutions (e.g. $4 \times 4 \mathrm{~km}$ grid in Dabbeek and Silva, 2019), similar thematic uncertainties can evolve 
75 due to the profound differences between both spatially correlated hazard intensities, and when the calculated losses are mapped over regional administrative units (Dabbeek et al., 2020).

To the best of the authors' knowledge, consideration of different hazard footprints and spatial correlation of their intensity measures for the construction of aggregation entities for exposure modelling has been only seldomly discussed in the literature. For instance, Chen et al., (2004) described the importance of ensuring a consistent delimitation of the resolution of the exposure 80 model along with the spatial variation of the two considered hazards, earthquakes and hailstorms, that impose damage footprints of very different extents. Complementary, Douglas (2007) and Ordaz et al., (2019) have highlighted the importance of the geographical scale to represent the building exposure models that are affected differently depending on variable hazard footprints. The study reported in Zuccaro et al., (2018) is perhaps the most advanced framework in the state of the art for the construction of a common aggregation entity for multi-hazard risk assessment, referred to as the minimum reference unit (MRU). This

85 geographical unit coincides with the minimum resolution of analysis of input (i.e. hazard intensities and exposure model) and output elements (i.e. damage and loss estimates) and remarks that despite high-resolution hazard models, one would achieve neither an accurate risk assessment nor meaningful loss mapping if there is no compatibility between the cartographic representation of the building exposure model, the hazard footprints and their IM correlation.

A denser set of geocells in the same area occupied by a coarser regular-sized cell or administrative units provides a denser 90 arrangement of hazard intensity values (when there are local IM variations) to the set of fragility functions per considered hazard. When local IM variations are not sufficiently represented into finer aggregation entities during the vulnerability analysis, thematic uncertainties might appear in the mapping, visualisation and interpretation of the loss estimates. Therefore, besides the conventional epistemic and aleatory uncertainties linked to the hazard, exposure and vulnerability components, thematic uncertainties are also present in the risk chain when the loss metrics are mapped. Awareness of the thematic uncertainties as well as clear and meaningful vulnerability/ loss mappings towards the most relevant hazards a community is exposed to is necessary to improve urban planning, preparedness, mitigation strategies and emergency response actions (e.g. Pang, 2008; Aguirre-Ayerbe et al., 2018).

We can distinguish two types of approaches formerly proposed in the literature to investigate the exposure aggregation for natural hazard risk applications.

100 (1) To independently represent the building portfolio over a series of aggregation entities such as administrative units, or equidimensional regular grids, and explore their individual contribution to the uncertainty in the losses imposed by certain hazard(s) to ultimately select a representative aggregation model. This option has been explored in Bal et al., (2010), Frolova et al., (2017), Senouci et al., (2018) and Kalakonas et al., (2020) for seismic vulnerability applications, and in Figueiredo and Martina, (2016) for flood vulnerability. These studies discuss the weakness of the physical vulnerability mapping at the individual building scale and over coarse aggregation areas, and highlight the importance of finding an optimal resolution for building exposure modelling while minimizing the uncertainties in the losses estimates. However, these attempts did not explicitly address the spatial correlation or attenuation of the hazard intensity into the predefined aggregation areas, and focused on individual hazards rather than on multi-hazard applications.

(2) Aggregating the exposure models over variable resolution entities that are not necessary administrative boundaries. This has been done in fewer studies. For instance, Muis et al., (2016) assessed the global population exposure to coastal flooding (from storm surges and extreme sea levels) through the application of a hydrodynamic model based on unstructured grids to ensure sufficient resolution in shallow coastal areas. Scheingraber and Käser, (2019) explored the uncertainty in regional building portfolio location for seismic risk through the use of weighted irregular grids. This weighting was carried out as a function of the population density and not using any hazard IM or footprints. Scheingraber and Käser, (2020) described the advantages of 

seismic risk assessment on a regional scale. Alternatively, aggregating the building portfolio into anisotropic CVT-based geocells (Central Voronoidal Tessellations) is suggested by Pittore et al., (2020).

In this study, we have decided to aggregate the residential building exposure models following the latter aforementioned option, anisotropic CVTs. We are adapting and customizing their derivation to explicitly account for the combination between a lowcorrelated hazard intensity (tsunami inundation) and one exposure proxy (population density) as generating distributions of the centroids of the Voronoi regions. The aggregated building portfolios therein are used for earthquake and tsunami scenario-based risk applications. The use of risk-scenarios has increasingly shown to be useful to estimate physical and cascading damages from natural hazards (e.g. Levi et al., 2018), as well for risk-communication purposes (e.g. Birkmann et al., 2020). We have systematically investigated several risk scenarios for the residential building stock of Metropolitan Lima (Peru) classified in terms of one set of earthquake vulnerability classes and two sets of tsunami vulnerability classes. These building portfolios have been aggregated within six customized CVT models and administrative units at the highest resolution available (i.e. block level). Through the use of the respective set of fragility functions, we have independently calculated the direct losses from scenario-based physical vulnerability analyses (seismic ground-shaking and tsunami inundation). For such an illustrative application, we have considered six megathrust subduction earthquakes and their respective tsunamis with moment magnitudes ranging between 8.5 and 9.0. We are successively showing that the implementation of this approach is beneficial not only in finding a balance between accuracy and computational demand but also in the efficient representation of the loss estimates while reducing bias generated in the loss mapping. The role of the spatial correlation of both hazard intensities in the efficiency and accuracy of the CVT-based exposure models is also discussed. Since the main scope of this work is to investigate an efficient manner to aggregate the building exposure for risk applications to multiple hazards, we have not investigated the conditional probability relating to cascading events (e.g. Goda et al., 2018), instead, we have assumed that every seismic rupture produces a tsunami. Hence, we are not accounting for cumulative damage on buildings due to consecutive ground shaking and tsunami (e.g. Park et al., 2019; Negulescu et al., 2020; Goda et al., 2021) nor the risk to other seismically induced hazards (i.e. earthquake-triggered landslides, liquefaction, ground failure; e.g. see (Daniell et al., 2017)

\section{Methodology to construct variable-resolution exposure model for risk assessment to multiple hazards}

The proposed methodology is composed of the following steps:

1. Simulation of scenario-based hazards (i.e. earthquakes and tsunamis) with the same spatially distributed intensities required by each fragility assessment.

2. Construction of one (or a set of) representative focus map(s). This implies to select and rank (with numerical weights) the hazard intensities or exposure proxies.

3. Generation of CVT-based aggregation entities employing the focus map as an underlying generating distribution and with different numbers of seeding points.

4. Classification of the exposed building stock of interest into vulnerability classes per considered hazard and their aggregation into the CVT-based geographical entities.

5. Scenario-based risk assessment independently per hazard type and discussion of their associated thematic uncertainties in the loss mapping and visualisation.

The uncertainties in steps 3 and 5 are explored through the formulation of a condition tree. 


\subsection{Simulation of scenario-based hazards with spatially distributed intensities}

We employ numerical earthquake and tsunami scenarios to replicate historical or hypothetical future events to simulate spatially distributed hazard intensities. For earthquakes, we simulate ground motions from suitable GMPE (ground motion prediction equations). Cross-correlated ground motions are generated for the spectral-periods that serve the fragility functions as intensity measures (IM). For tsunamis, we employ the physical generation and propagation model TsunAWI (Harig et al., 2008) and simulate coastal inundation as IM for tsunamis. The spatially distributed tsunami intensity values (inundation flow depth) are compatible with the IM of the selected set of fragility functions required in the vulnerability analysis.

\subsection{Construction of focus maps}

The focus map drives the construction of a variable-resolution exposure model for aggregating building portfolios. Focus maps were first introduced by Pittore (2015) based on the work of Dilley (2005), which proposed the spatial representation of composite indicators in hot-spots. Eq. (1) recalls the definition of a focus map, $S\left(D_{i}\right)$, that represents the probability of each location to be highlighted, given the actual values of certain indicators $D_{i}$.

$$
S\left(D_{i}\right)=P\left(S \mid D_{i}\right) \in[0,1]
$$

Through the use of a pooling operator, a focus map highlights areas where a weighted combination of various normalized spatially distributed indicators $\left(D_{i}\right)$ jointly assume the larger values. We propose to obtain a focus map that drives the aggregation entities for earthquake and tsunami exposure modelling through the combination of two indicators. (1) Population density $\left(D_{0}\right)$ (from aggregated data sources e.g. WorldPop; GPWv4 (CIESIN, 2018)). This indicator is an exposure proxy about the location of residential buildings for which their ground-shaking vulnerability should be addressed. The use of the latter can be a useful indicator when other seismic risk components such as soil amplification conditions are poorly known; come from proxies with coarse resolutions (e.g. topography-based); or when strong seismic site effects are not expected. (2) The tsunami component is constrained through the expected tsunami inundation height $\left(D_{1}\right)$ obtained from a "worst-case scenario" approach (i.e. largest feasible intensities) among a series of deterministic scenarios (e.g. Omira et al., 2009; Wronna et al., 2015). For the combination of the two aforementioned normalized input layers, we use a log-linear pooling operator $P_{G}$ of Eq. (2). This algorithm assigns a higher sampling probability to spatial locations where both indicators are relevant while penalizing the locations where at least one of the indicators (i.e. tsunami) is negligible.

$$
\ln P_{G}\left(P\left(S \mid D_{0}\right), P\left(S \mid D_{1}\right), \ldots P\left(S \mid D_{n}\right)\right)=\ln Z+\sum_{i=0}^{n} w_{i} \ln P\left(S \mid D_{i}\right)
$$

Where $\mathrm{Z}$ is a normalizing constant and $\mathrm{w}_{\mathrm{i}}$ represents the respective weight assigned to score the relevance of each input layer, and $\sum w_{i}=1, w_{i}>0 \forall i$. Thus, the construction of a focus map entails the selection of the weights that rank the importance of every layer, as such carries its own epistemic uncertainties.

\subsection{Generation of CVT-based exposure models}

180 Selectively increasing the spatial resolution in aggregation areas is beneficial to capture the low spatially correlated hazard intensity values such as tsunami inundation heights. This is achieved by the construction of geocells with variable resolution in the form of Central Voronoi Tessellations (CVT), as proposed by Pittore et al., (2020). During this construction, focus maps are used as underlying generating spatial intensities and are sampled using a Poisson point process (Cox and Isham, 1980) to generate a number of seeding points. These points will be used as centroids of the Voronoi geocells and through an iterative relaxation process will 
185 converge to the final CVT geocells. The number of seeding points is therefore defining the number of geocells of the resulting tessellation. CVTs are computed in various iteration steps using the simple relaxation method originally proposed by Lloyd (1982) until the distance between the geometrical centroid of the geocell and the weighted mass centroid generated by the raster distribution falls below a defined threshold, or after a given maximal number of iterations achieved. Since the relaxation process is based on the underlying focus maps as generating distribution, CVT cell sizes are inversely proportional to the intensity of the

190 focus map. Each CVT geocell by fact becomes a minimum resolution unit as proposed in Zuccaro et al., (2018), and the resulting tessellation sets the basis for a variable-resolution exposure model.

\subsubsection{Condition tree for multi-hazard exposure modelling}

The epistemic uncertainties underlying the two former steps are explored using a condition tree with the following hierarchical levels:

i. Selection of a suitable scheme (sets of building classes and their associated fragility functions) to describe the building inventory in the study area for risk assessment.

ii. Weight arrangement values $\left(w_{i}\right)$ that rank every input layer (low spatially correlated hazard intensities or spatial proxies related to the exposure component) in the focus map construction.

iii. Determination of the number of seeding points sampling the Poisson Point Process driven by a focus map that drives the generation of CVT-based geocells.

The condition tree presents a summary of assumptions for uncertainty treatment (Beven et al., 2018). Through the construction of alternative multi-resolution exposure models, the impact of every level of the conditional three is systematically investigated once the vulnerability assessment is performed.

\subsection{The classification of the building stock into vulnerability classes and aggregation}

205 The building stock of interest is classified in terms of several sets of mutually exclusive, collectively exhaustive vulnerability classes, whose aggrupation describe a set of classes (scheme) specific to the considered hazard (i.e. earthquake and tsunami). A top-down approach is used making use of aggregated census data and ancillary data for the seismic-oriented building classes. Subsequently, the proportions assigned to each seismic-oriented building classes are reassigned to tsunami oriented classes through the use of inter-scheme compatibility matrices as recently presented in Gomez-Zapata et al., (2021). This method is partly based on the taxonomic disaggregation of every building type within a source and a target scheme as proposed by Pittore et al., (2018) for seismic vulnerability applications, as well as strongly suggested by Charvet et al., (2017) for the definition of tsunami oriented building classes. Then, the classified building stocks are aggregated into every CVT model obtained in the former step.

\subsection{Scenario-based risk assessment}

The fragility of the building portfolio to the considered earthquakes and tsunami scenarios is calculated separately over every

215 aggregation exposure models obtained in Sect. 2.1. This decision is based on the recent findings of Petrone et al., (2020) who found fundamentally different structural responses to both perils. As a consequence, the authors argued that the intensity of the seismic ground motion does not play a significant role in the building's structural tsunami response unless it induces structural yield. The latter is assumed for the vulnerability analysis considering the sole objective of this study of evaluating an optimal exposure model for risk assessment from the considered hazards. The scenario-based risk assessment makes use of a set fragility function associated

220 with each building class and whose IMs are compatible with the hazard intensities modelled in Sect. 2.1. Each of their damage states has an assigned loss ratio to total replacement cost per hazard-dependent building class. 


\section{Application example}

\subsection{Context of the study area: Metropolitan Lima, Peru}

225 According to Petersen et al., (2018), Peru, among all the South American countries, has the largest number of inhabitants, which with a $10 \%$ probability of exceedance in 50 years, may experience a ground-shaking greater than VIII (modified Mercalli intensity scale, MMI). This makes Peru the country in which the largest average annual fatalities from earthquakes are expected in South America. In the same study, Lima, with nearly 10 million inhabitants has been identified as the capital city exposed to the highest seismic hazard in the region. This is in line with Salgado-Gálvez et al., (2018). Earthquakes are mostly attributed to the oceanic

230 Nazca Plate subducting beneath the South American plate (Villegas-Lanza et al., 2016). In 1746 a giant megathrust earthquake with an estimated magnitude of Mw 8.8 (Jimenez et al., 2013) ruptured along some $350 \mathrm{~km}$ and triggered a tsunami with local runup heights of 15 to $20 \mathrm{~m}$ (Dorbath et al., 1990). These events completely destroyed Lima and Callao. The less studied events of 1586 and 1724 triggered tsunami run-ups over 24 m (Kulikov et al., 2005). Moreover, according to Løvholt et al., (2014), Peru has the largest population exposed to tsunami hazard in the American continent, with Lima representing $\sim 1 / 3$ of the total country's

235 population. The most important economic activities as well as the main port of the country are located in the study area. Consequently, in Schelske et al., (2014), Lima has been ranked as the second metropolitan area in the world in terms of the value of working days lost relative to the national economy due to earthquakes. This highlights the relevance of integrated vulnerability studies in this study area for the overall economy of Peru.

Local authorities have conducted studies for emergency management and recovery planning considering tsunami and

240 earthquake scenarios (e.g. PREDES, 2009) including qualitative risk estimations. Among others, the Japanese SATREPS project contributed to the improvement of the exposure model of Lima using satellite imagery and census data (Matsuoka et al., 2013). On the seismic vulnerability side, the project SARA, led by the Global Earthquake Model (GEM), made a large contribution to classify the residential building stock of Peru (Yepes-Estrada et al., 2017) and associate a fragility function per class (Villar-Vega et al., 2017). More specific models for confined masonry have been reported in Lovon et al., (2018). On the tsunami vulnerability

245 side, Adriano et al., (2014) estimated tsunami damage probabilities for two tsunami scenarios over the residential building portfolio classified into four building classes and employing the empirical tsunami fragility functions developed by Suppasri et al., (2013) after the 2011 Japan tsunami. Ordaz et al., (2019) analysed the probabilistic physical risk to both hazards in Callao.

\subsection{Construction of earthquake and tsunami scenarios for Lima}

250 We have simulated six earthquakes and tsunami scenarios off-shore Peru moment magnitudes Mw 8.5 to 9.0. Finite fault ruptures are modelled using the OpenQuake engine (Pagani et al., 2014) emulating the historical earthquake that occurred in 1746. The basic parameters used in the simulation are; hypocentre location (longitude $=-77.93^{\circ}$; latitude $=-12.19^{\circ} ;$ depth $=8 \mathrm{~km}$ ); strike $=$ $329^{\circ}$; dip $=20^{\circ}$, rake $=90^{\circ}$. Replicating the 1746 earthquake is in line with former studies (e.g. Mas et al., 2014; Pulido et al., 2015; Ceferino et al., 2018a). Spatially distributed ground motion fields are generated using the GMPE proposed in Montalva et al., (2017). Its site term is based on the shear wave velocity in the uppermost 30 meters depth $\left(\mathrm{Vs}_{30}\right)$ reported in Ceferino et al., (2018b) in which the slope-based $\mathrm{Vs}_{30}$ values (Allen and Wald, 2007) and a seismic microzonation (Aguilar et al., 2013) were compiled and merged to the same resolution (30 arc-seconds $\sim 1 \mathrm{~km}$ ). The aleatory uncertainty in the ground motions is addressed by generating 1,000 realisations per event, as advised in Silva (2016) with uncorrelated and cross-correlated ground motions using the Markhvida et al., (2018) model for PGA, $0.3 \mathrm{~s}$ and 1.0 s. Examples of three selected seismic ruptures (Mw 8.6, 8.8, and 9.0), and respective tsunami scenarios are shown in Figure 1. 


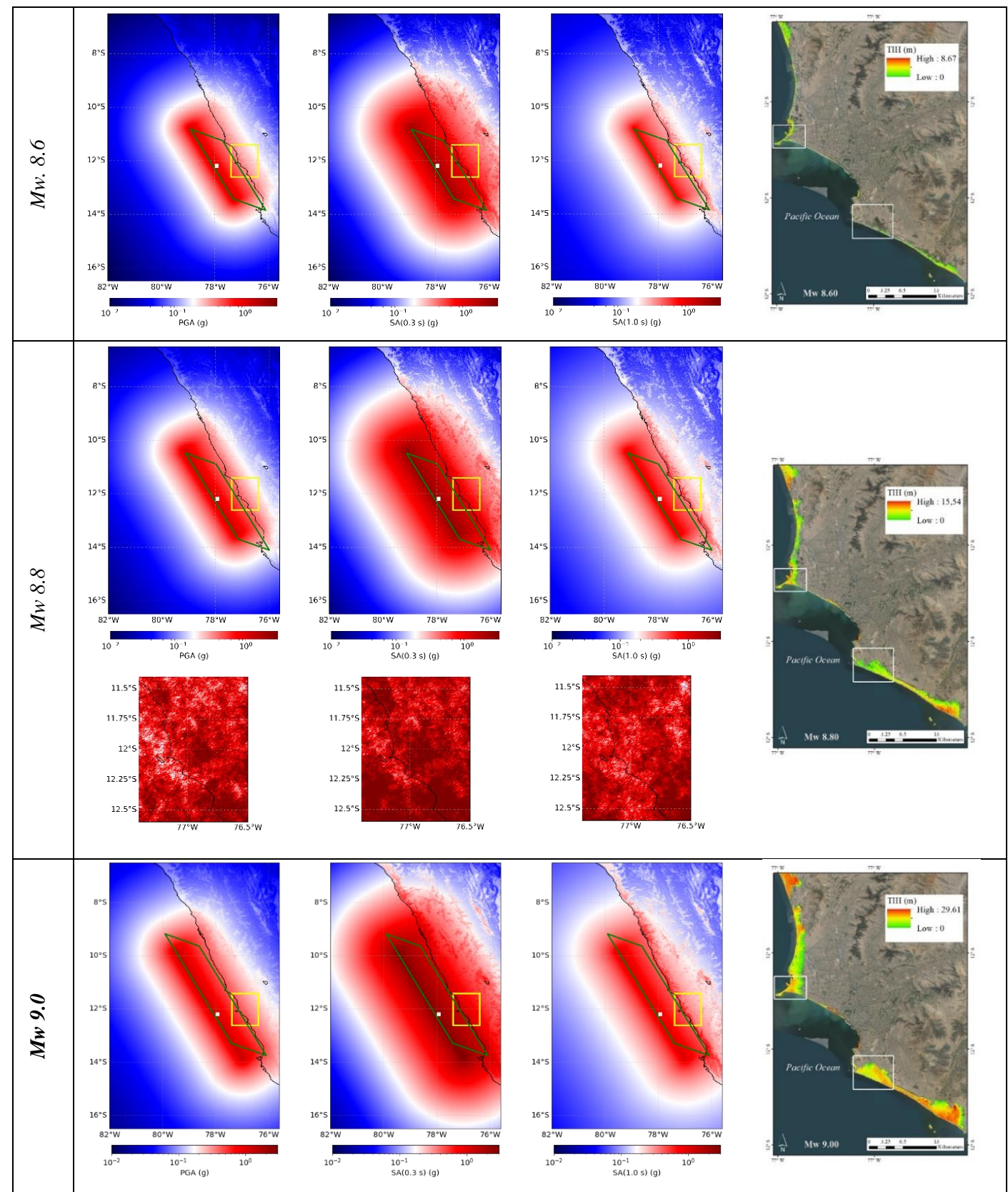

Figure 1. Median seismic ground motion for a single realisation using the Montalva et al., 2017 GMPE for PGA, $0.3 \mathrm{~s}$ and $1.0 \mathrm{~s}$, and three earthquake ruptures ( $\mathrm{Mw}$ 8.6, 8.8 and 9.0) along the Peruvian subduction zone. Green rectangles represent a random rupture plane.

Hypocentres are shown by white dots. Metropolitan Lima is enclosed within a yellow rectangle. For this area, and for the Mw 8.8 scenario, there is shown one realisation of spatially cross-correlated ground motion field per spectral acceleration. Tsunami inundation heights are 
Tsunami simulations are based on the source parameters suggested in Jimenez et al., (2013). We fixed all earthquake parameters except for the slip value specifying the magnitude over a range from Mw 8.5 to Mw 9.0. This simplifies the simulation process and allows for a more systematic study of the contribution of the event's magnitude and the corresponding tsunami footprint upon the loss assessment for the aggregated building exposure models. The wave propagation and tsunami inundations are obtained through a numerical simulation with the finite element model TsunAWI using a triangular mesh with variable resolution, with the smallest triangle edge length reaching $5 \mathrm{~m}$ in the coastal area of Lima and Callao to simulate inland inundation with the highest resolution. The corresponding topography data in this region are based on the measurements of the TanDEM-X mission and given at a spatial resolution of $12 \mathrm{~m}$. Since the unstructured model output is cumbersome to process and visualize, the results are interpolated to a raster file. According to the mean resolution of the triangular mesh, a raster with grid cell dimensions of $10 x 10 \mathrm{~m}$ was chosen. Details of this method are reported in Harig et al., (2020). Tsunami inundation height for the six scenarios over the two most tsunami-prone areas in the Lima city -La Punta and Chorrillos district- (see the white square in tsunami maps of Figure 1) are shown in Figure 2. Conversely, significant tsunami inundation is not expected in the central Lima area due to the presence of distinctive cliffs.

(a) La Punta sector (Callao district)

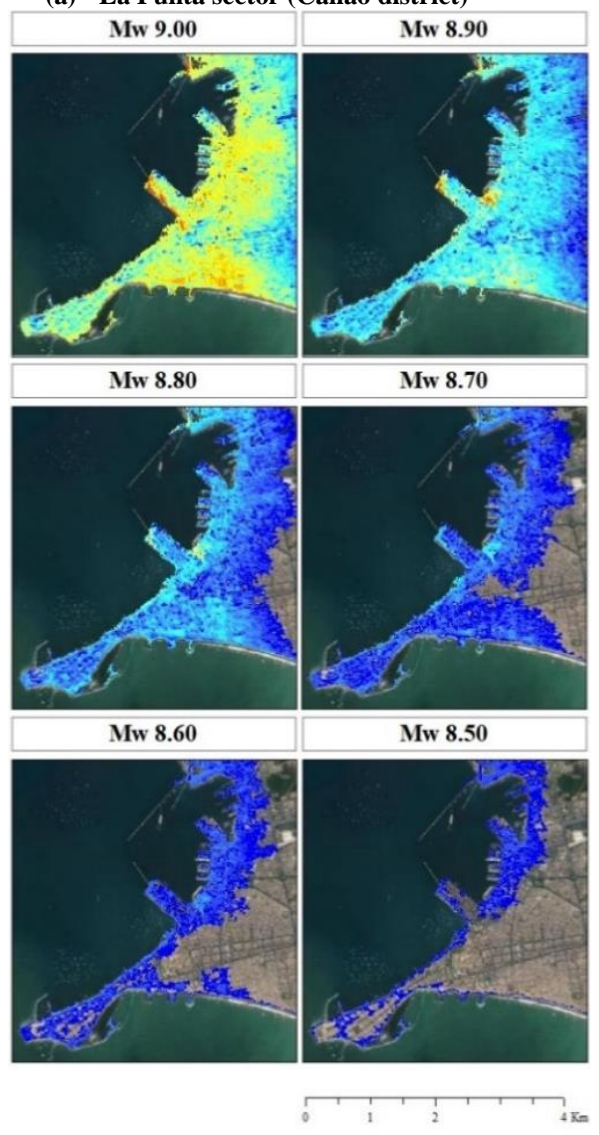

(b) Chorrillos district
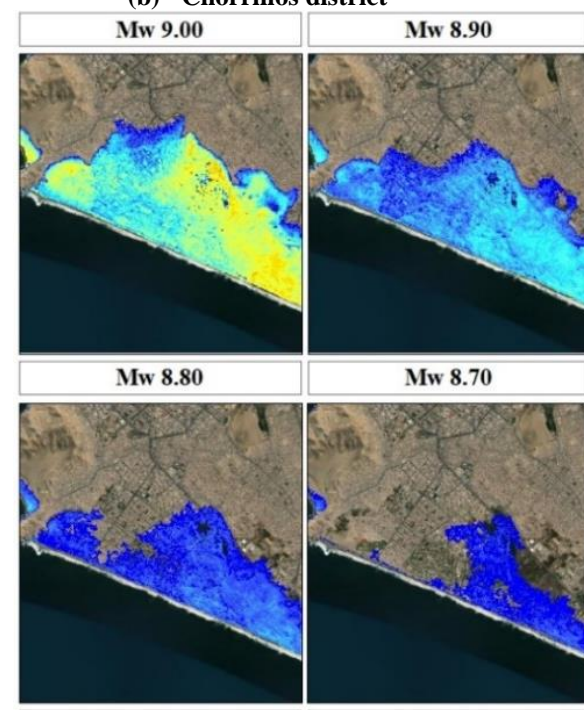

Mw 8.70

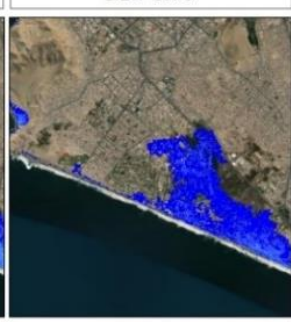

Mw 8.50
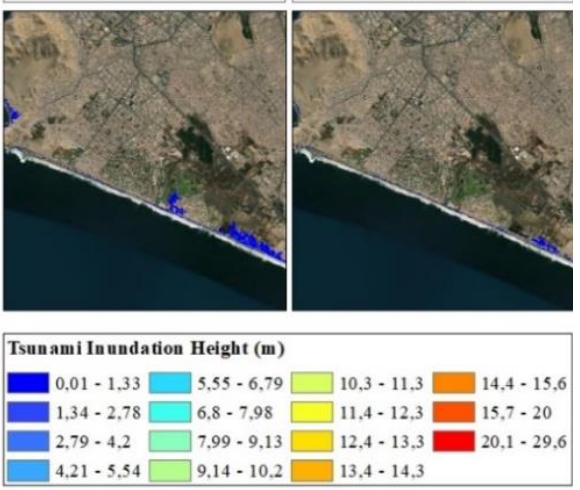

Figure 2. Expected tsunami inundation height $(\mathrm{m})$ for two local areas within the Lima city for six tsunami scenarios. Map data: @Google Earth 2021. 


\subsection{Construction of the focus maps}

285 Focus maps have been constructed as inputs to generate CVT-based aggregation boundaries for the building exposure model for seismic and tsunami risk assessment. The spatial population density (PD) in Lima at the block level (INE, 2017) has been combined with a "worst-case" scenario of tsunami inundation height (TI). Distribution of the ground motion has not been used, because, besides its high spatial correlation, negligible nonlinear soil effects in the study area (Pulido et al., 2015) would not allow the visualisation of seismic-intensity-driven hot-spots within a focus map. A Mw 9.0 tsunami scenario was selected among a catalogue of 1,000 offshore scenarios for Lima/Callao that range by magnitude from Mw 8.0 to Mw 9.0. Both map layers have been linearly normalized and combined using the log-linear pooling expressed in Eq. (2) in order to assign a higher probability to the spatial locations where both indicators are relevant. Two sets of weights that rank and combine the layers have been selected to perform a sensitivity analysis at this step. In both sets, tsunami intensities were ranked higher as population density due to their lower spatial correlation. The following weights were accepted for the construction of two focus maps: set (1) PD = 30\% - TI = 70\%, and set (2) $\mathrm{PD}=40 \%-\mathrm{TI}=60 \%$, and create the basis for the condition tree presented in Figure 3 . The construction of the focus map for the first set is shown in Figure 4-a.

\subsection{Generation of CVT-based exposure aggregation boundaries.}

Three seeding sets have been generated by sampling the heterogeneous Poisson point processes defined by the two focus maps including 5,000, 10,000 and 50,000 initial points. We have obtained six CVT aggregation entities for residential building exposure modelling by applying the Lloyd relaxation method as described in Pittore et al., (2020) and recalled in Sect. 2.3. As an example, the resultant CVT-based model obtained from the focus map from set (1) PD $=30 \%$ - TI $=70 \%$, and the 5, 000 seeding points (model PD30_TI70_5,000) is depicted in Figure 4-b. The area jointly exposed to the earthquakes and to the largest tsunami footprint (Mw 9.0) is highlighted in pink colour. The distribution of $\mathrm{Vs}_{30}$ values in the study area within this CVT-based example is shown in Figure 5. Due to the contribution of the population density layer (PD), for every $\mathrm{Vs}_{30}$ value at each location, there is a higher density of IM values that are computed where the exposed assets are expected to be concentrated rather than in the locations less densely populated, in contrast with what would occur using a regular grid.

\subsection{Classification of the building stock into vulnerability classes and aggregation}

310 The residential building stock of Metropolitan Lima (Peru) has been classified in terms of one scheme oriented to seismic vulnerability and into two tsunami schemes with related building classes. They have been constructed following Sect. 2.4 and the logical steps depicted in the flowchart in Figure 3. The initial input is the official census dataset for Lima compiled by the Peruvian statistics institution (INE, 2017) at the block level. It offers the number of buildings for each block and a few exposure attributes regarding the type of dwelling, floor and façade predominant materials at the dwelling level. The mapping-scheme proposed

315 through expert elicitation in the SARA project (GEM, 2014; Yepes-Estrada et al., 2017) for Peru has been used to relate the census attributes with the proportions expected for 21 building classes. Subsequently, the dwelling fractions (per building unit) proposed in the same study have been used to obtain the building counts for every urban block. Subsequently, the building portfolio is spatially distributed into every CVT-based model through a simple disaggregation procedure addressing their mutual intersections with the block-based model.

320 Two tsunami reference schemes are selected to classify the building stock of Metropolitan Lima, namely Suppasri et al., (2013) and De Risi et al., (2017) to explore the epistemic uncertainty in their classification. While the first one addresses ten 
building classes in terms of predominant material and number of stories, the second only accounts for four classes solely in terms of material. Steel classes are not included since they have not been deemed representative in Lima (Yepes-Estrada et al., 2017). Thus, we keep seven and three classes respectively. Considering SARA as the source scheme, the approach presented in GomezZapata et al., (2021) was used to obtain the SARA-Suppasri et al., (2013); SARA-De Risi et al., (2017) inter-scheme compatibility matrices shown in Figure 6. Through their use, the building stock is represented in terms of the building classes of the target tsunami schemes.

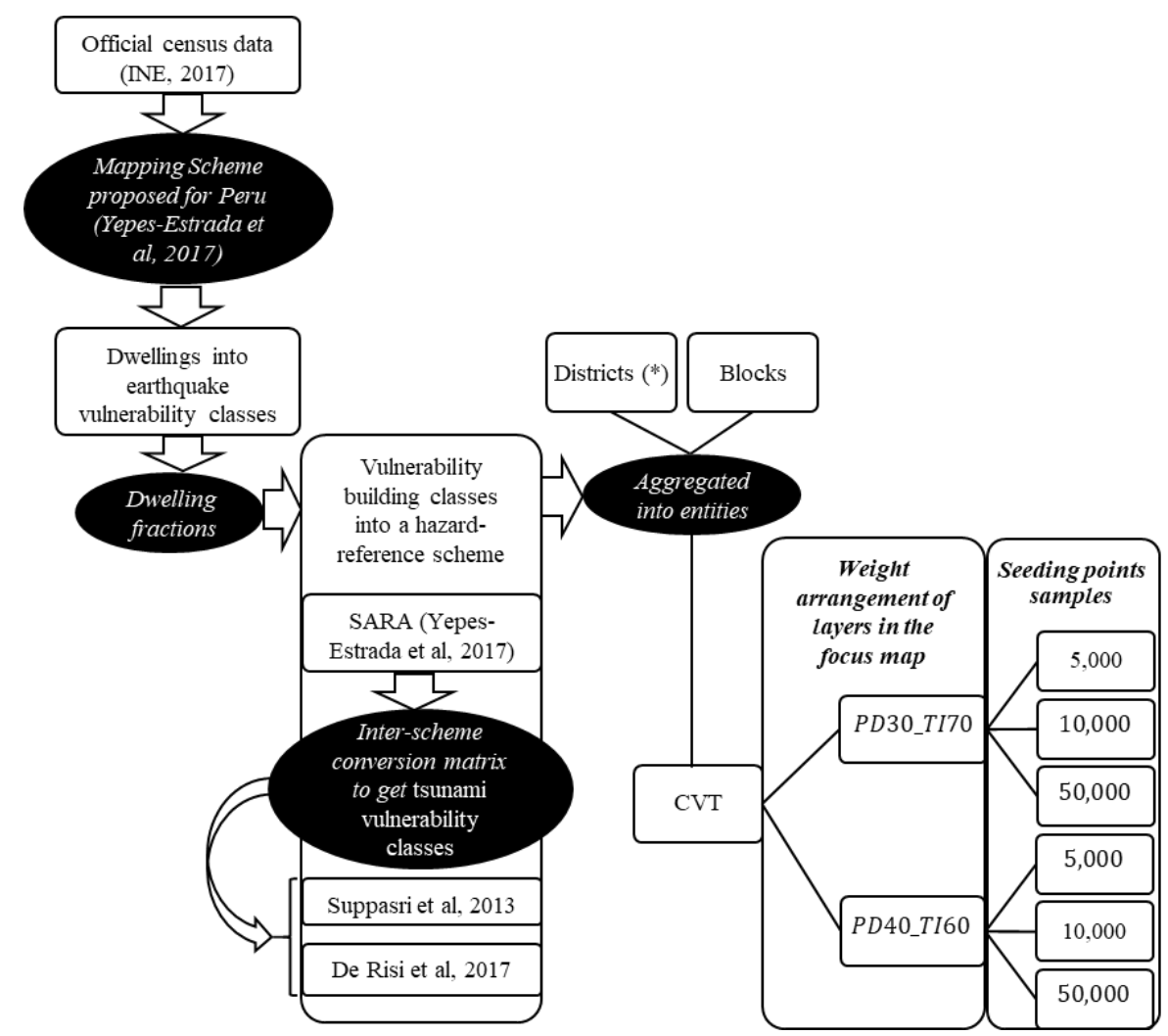

330 Figure 3. Flowchart used to construct the building exposure model for Metropolitan Lima including the condition tree used for the construction of CVT-based exposure models for the aggregation of earthquake and tsunami vulnerability building classes. (*District-based aggregation entities are only used for seismic risk to compare absolute loss values)

Every building portfolio for the two considered hazards is aggregated upon the block-based aggregation entities: the six CVTbased and, only for seismic risk (using SARA), over the Peruvian third administrative level division (districts). The building class frequency distribution in the "La Punta" sector (Callao) is depicted at the block level in Figure 7-a,b in terms of the seismic oriented-SARA scheme and in Figure 7-c,d in terms of the two selected tsunami schemes. 
https://doi.org/10.5194/nhess-2021-70

Preprint. Discussion started: 16 March 2021

(c) Author(s) 2021. CC BY 4.0 License.

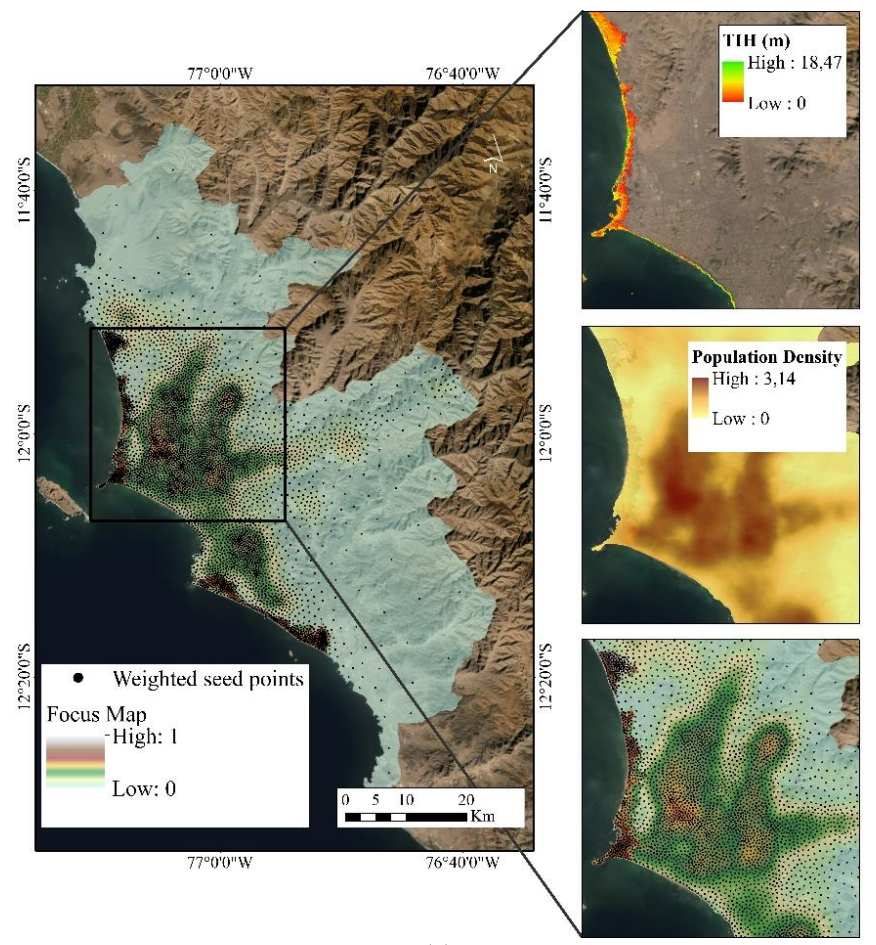

(a)

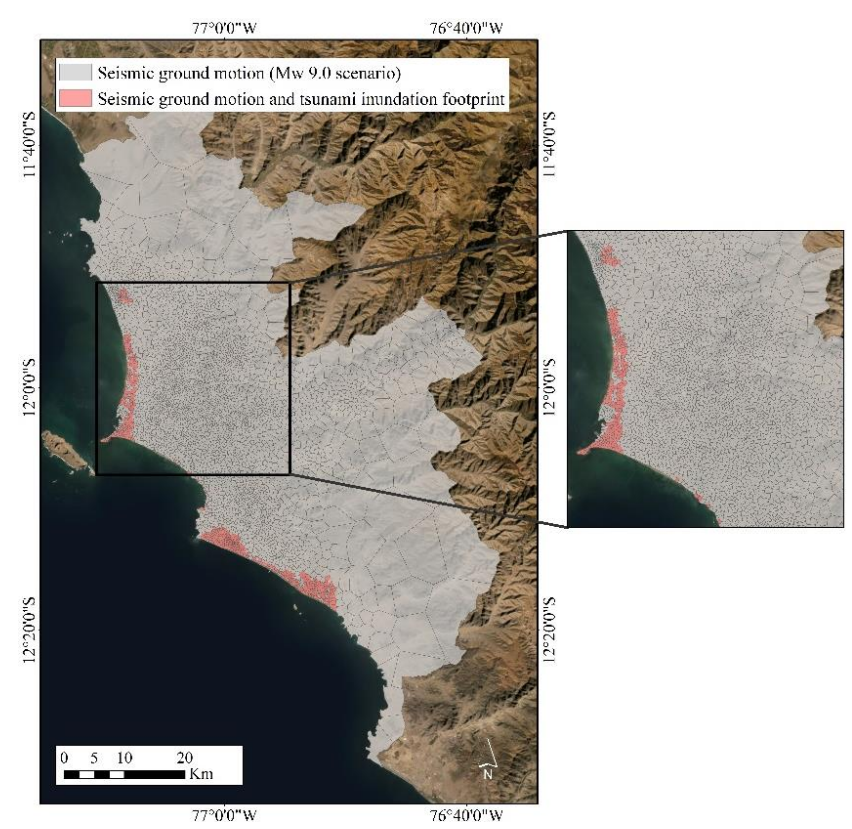

(b)

Figure 4. Example of the construction of focus map and CVT models in Lima: (a) 5,000 weighted seeding points sample a focus map through a Poisson point process. The normalised focus map is constructed from a log-linear pooling algorithm of the combined layers (population density

(PD) and tsunami inundation height (TI) with a selection of $30 \%$ and $70 \%$ weights respectively). (b) The resultant CVT geocells. The commonly exposed area to a Mw 9.0 earthquake and tsunami is coloured in pink whilst the area only exposed to seismic risk is coloured in grey. Map data: ()Google Earth 2021. 
https://doi.org/10.5194/nhess-2021-70

Preprint. Discussion started: 16 March 2021

(c) Author(s) 2021. CC BY 4.0 License.

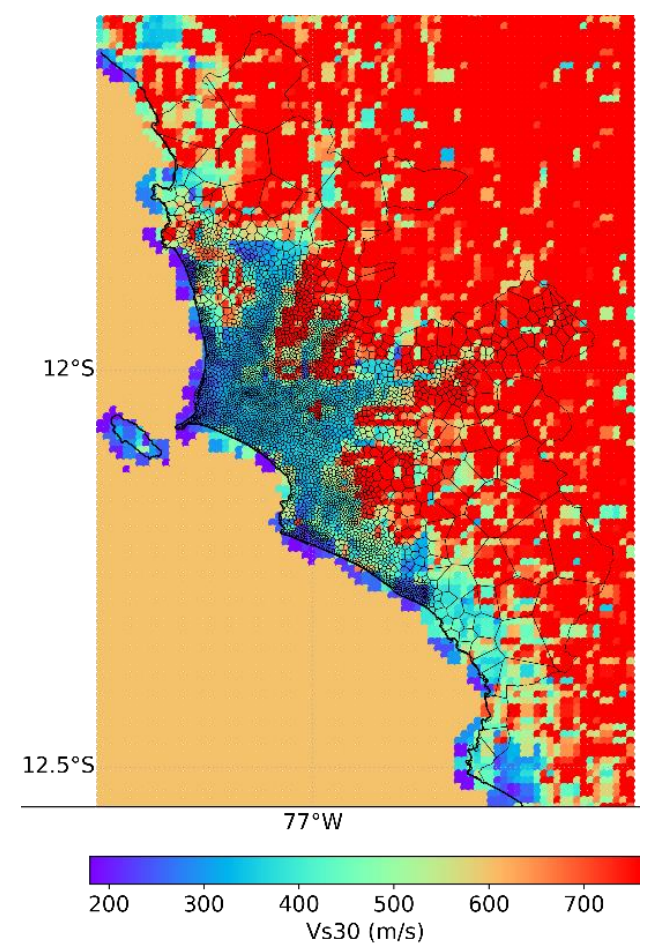

(a)

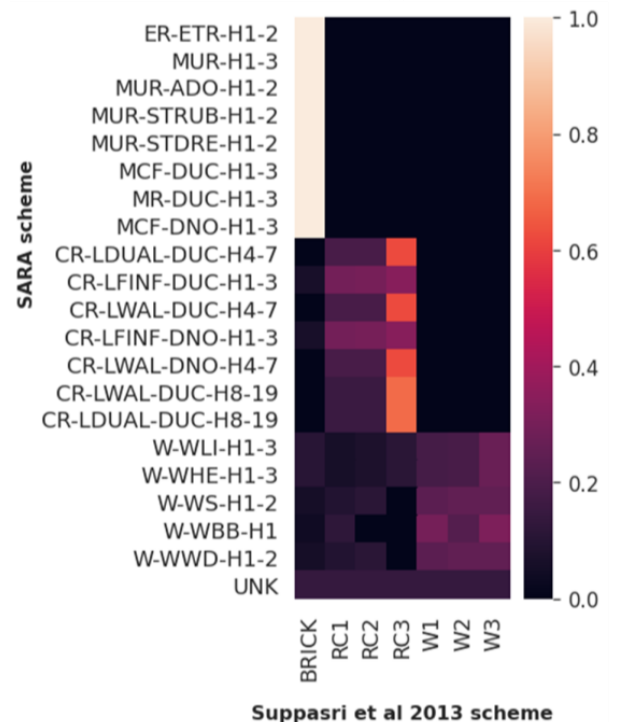

(b)

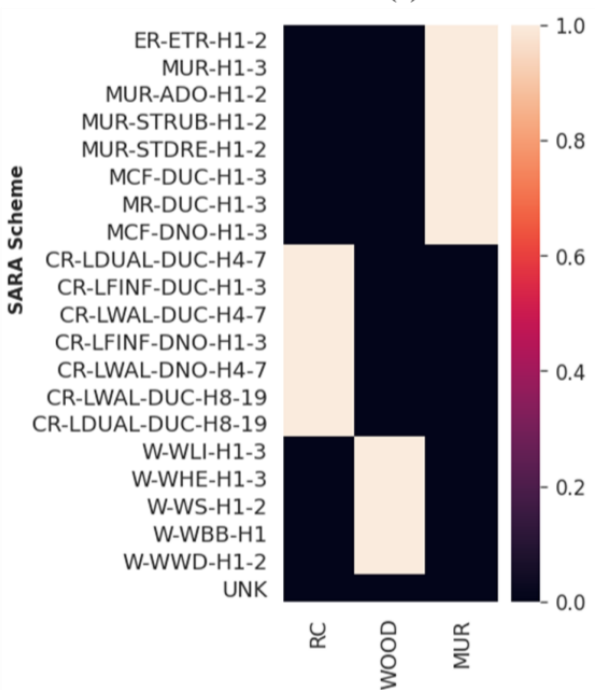

De Risi et al, 2017 scheme

355 Figure 6. Inter-scheme compatibility matrices for Lima showing the compatibility level between the seismic-oriented reference scheme SARA and the tsunami-oriented target schemes: Left: Suppasri et al., 2013 and Right: De Risi et al., 2017. 


\section{Building class composition in the "La Punta" sector (Callao) in terms of three reference schemes}

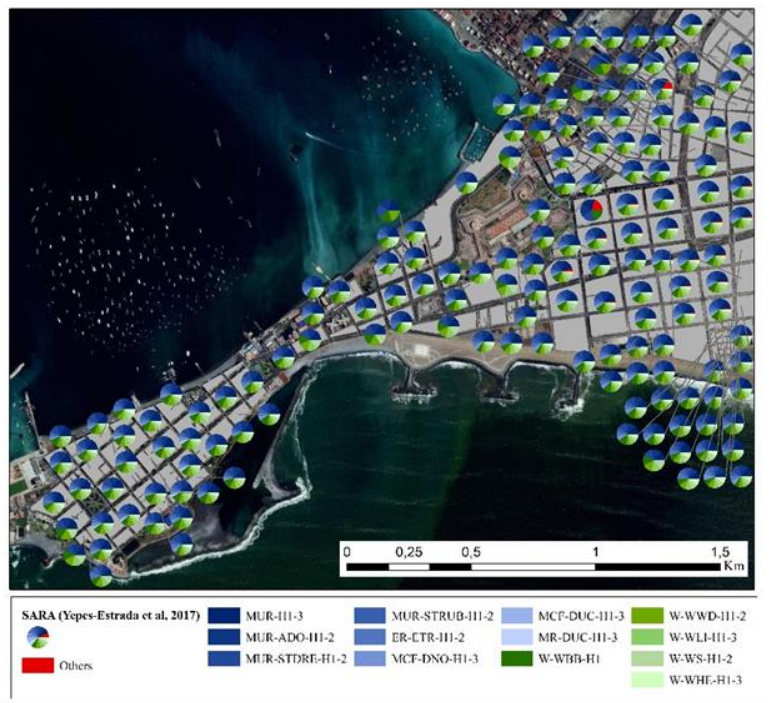

(a)

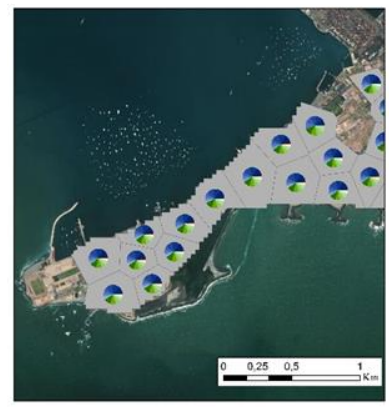

(b)

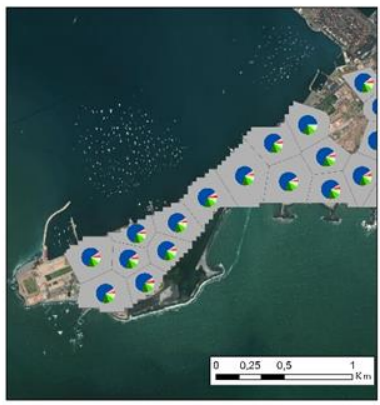

$\begin{array}{lll}\text { Suparsi et al, 2013 } & \text { RC3 } \square \text { RC1 } \\ \text { RC2 } & \text { W3 } \\ \text { BRICK } & \text { W2 }\end{array}$

(c)

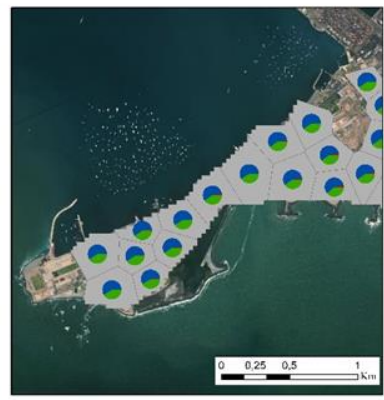

De Rissi et ut, 2017 RC Mt:R wooD

(d)

Figure 7. Example of the building class frequency distribution in "La Punta" (Callao) mapped using the seismic oriented- SARA scheme (Yepes-Estrada et al., 2017) (a) at the block level (b) on the CVT based model PD30_TI70_5,000. The latter model is used to aggregate the tsunami vulnerability oriented building classes: (c) Suppasri et al., 2013 and (d) De Risi et al., 2017. Map data: @Google Earth 2021.

\subsection{Results: scenario- based risk assessment}

As suggested by Petrone et al., (2020) due to the fundamentally different structural responses to both perils, the direct economic losses of the aggregated building portfolios for six scenario earthquakes and the corresponding tsunamis have been separately estimated. Hence, all effects related to cumulative damage have been disregarded. The variability of aggregation areas that form every residential building exposure model of the entire Lima/Callao is depicted in Figure 8-a, and listed in Table 1-a. Conversely, if we narrow down the exposed area to the largest tsunami footprint (Mw 9.0), we see that the variability in aggregation areas is very different (Figure 8-b). The CVT-based models with higher resolutions $(50,000)$ geo-cells can reach very fine areas when the focus map considers the weights $\mathrm{PD}=30 \%-\mathrm{TI}=70 \%$. Whilst the block model can reach the largest area values. Moreover, the 
model PD30_TI70_50,000 provides a larger number of geo-cells and with a very similar representation area with respect to the non-contiguous block-based model (Table 1-b). Furthermore, from Table 1-a we can see that the computational effort required to construct the various exposure models only in terms of file size.
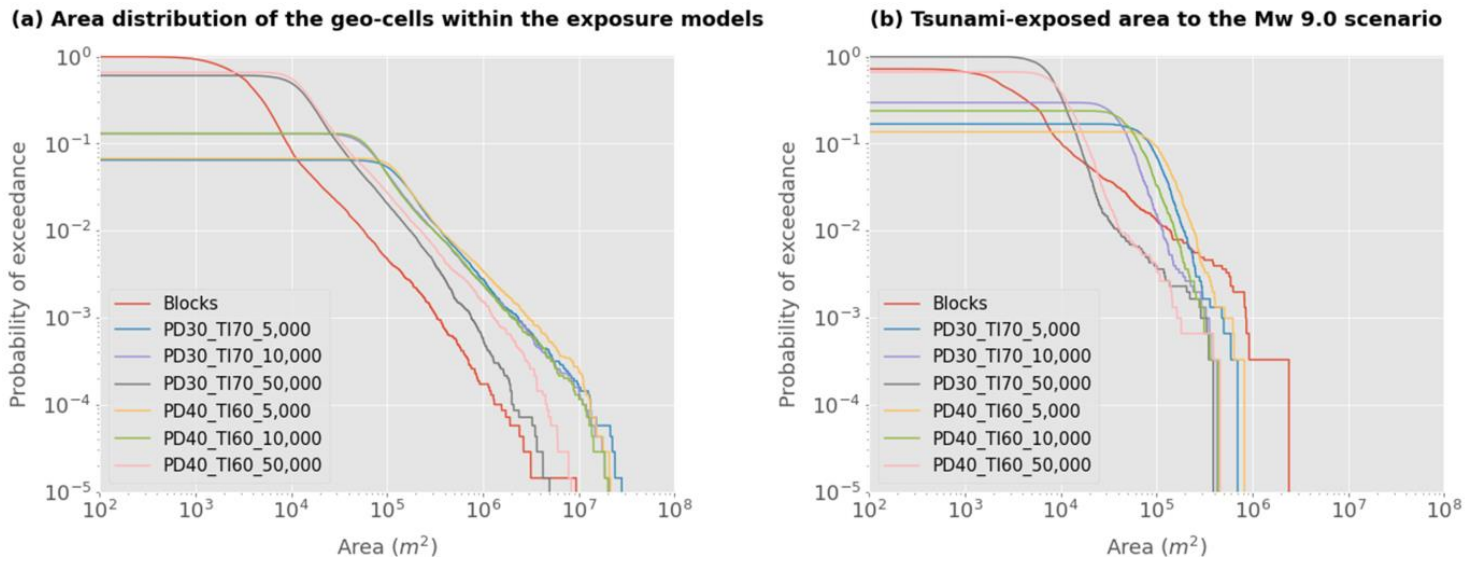

Figure 8. Variability in the area (in meter square) of the geocells that compose every exposure model for (a) the entire urban area of Lima; (b)

Table 1. Variability in the area of the exposure models proposed for (a) the entire urban area of Metropolitan Lima, and (b) for the exposed area to the Mw 9.0. Only geocells that are intersected with an urban land use are considered.

\begin{tabular}{|c|c|c|c|c|c|c|}
\cline { 2 - 7 } \multicolumn{1}{c|}{} & \multicolumn{3}{c|}{$\begin{array}{c}\text { (a) Configuration in the entire urban area of } \\
\text { Metropolitan Lima }\end{array}$} & \multicolumn{2}{c|}{$\begin{array}{c}\text { (b) Mapped as having suffered tsunami- induced } \\
\text { loss from the Mw 9.0 scenario }\end{array}$} \\
\hline Exposure model & $\begin{array}{c}\text { Number of } \\
\text { geocells }\end{array}$ & $\begin{array}{c}\text { Area mapped } \\
\left(\mathrm{m}^{2}\right)\end{array}$ & $\begin{array}{c}\text { Input size } \\
\text { file (MB) }\end{array}$ & $\begin{array}{c}\text { Number of } \\
\text { geocells }\end{array}$ & $\begin{array}{c}\text { Area mapped } \\
\left(\mathrm{m}^{2}\right)\end{array}$ & $\begin{array}{c}\text { Output size } \\
\text { file (MB) }\end{array}$ \\
\hline PD30_TI70_5,000 & 4,544 & $1,500,190,674$ & 5.3 & 513 & $54,193,102$ & 0.220 \\
\hline PD40_TI60_5,000 & 4,722 & $1,695,823,202$ & 6.0 & 416 & $57,449,037$ & 0.227 \\
\hline PD30_TI70_10,000 & 9,124 & $1,559,962,251$ & 11 & 906 & $47,494,288$ & 0.431 \\
\hline PD40_TI60_10,000 & 9,182 & $1,554,137,115$ & 10.5 & 728 & $51,493,317$ & 0.302 \\
\hline PD30_TI70_50,000 & 42,509 & $1,194,376,921$ & 45.9 & 3,044 & $32,496,805$ & 1.100 \\
\hline PD40_TI60_50,000 & 46,217 & $1,537,815,051$ & 53.7 & 2,034 & $28,418,986$ & 1.010 \\
\hline Block-based & 69,786 & $468,884,278$ & 118.6 & 2,203 & $29,659,921$ & 1.700 \\
\hline
\end{tabular}

\subsubsection{Seismic risk}

Seismic losses for the entire study area are initially presented for a selected Mw 8.8 earthquake scenario in order to discuss the implications of the resolution of the exposure model in the economic loss estimates as well as on their associated mapping and visualisation. A comparison for the other five earthquake scenarios is provided in section 3.6.3 for the commonly exposed area to ground-shaking and tsunami inundation. As formerly described, the residential building stock of Lima is classified in terms of the SARA scheme and aggregated considering eight different geographical models (six CVT-based, one block, and one district-based model). Each building class has an associated analytically derived fragility function provided in Villar-Vega et al., (2017) as well 
as their respective economical replacement cost reported in Yepes-Estrada et al., (2017). We have assumed loss ratios 2\%, 10\%, $50 \%$, and $100 \%$ as suggested by FEMA, (2003) for each of the four damage states considered in the vulnerability model. Similar values have been recently proposed for seismic risk applications (e.g. Martins and Silva, 2020).

The seismic vulnerability analysis is performed at every geocell-centroid, where the buildings are aggregated. We consider each IM value resulting from 1,000 realisations of spatially cross-correlated and uncorrelated ground motion fields. The resultant distributions for the Mw 8.8 scenario are displayed in Figure 9. Uncorrelated ground motion fields led to very homogeneous distributions, except at the district level. This finding is aligned with the recent study presented by Scheingraber and Käser, (2020). Moreover, the latter confirms that if the dimension of the geocells in the exposure model is larger than a typical seismic ground motion correlation length (i.e. $20 \mathrm{~km}$ ), an artificial bias in the ground motion correlation has to be expected as described in Stafford (2012). We obtain larger median loss values from uncorrelated ground motions. We observe that for the considered scenario, the median loss values are insensitive to the aggregation of the exposure model at varying resolutions. This feature was already described in Bal et al., (2010) for a crustal earthquake damaging a building portfolio in Istanbul while neglecting the crosscorrelation model. We are thus confirming the finding reported in Bal et al., (2010) while further expanding it when a ground motion cross-correlation model is actually considered. Despite these remarkable differences between the areas distributions of the models (Figure 8, Table 1), we do not observe significant differences in the associated absolute seismic-induced losses, which is explained by the high special correlation of seismic ground motion.

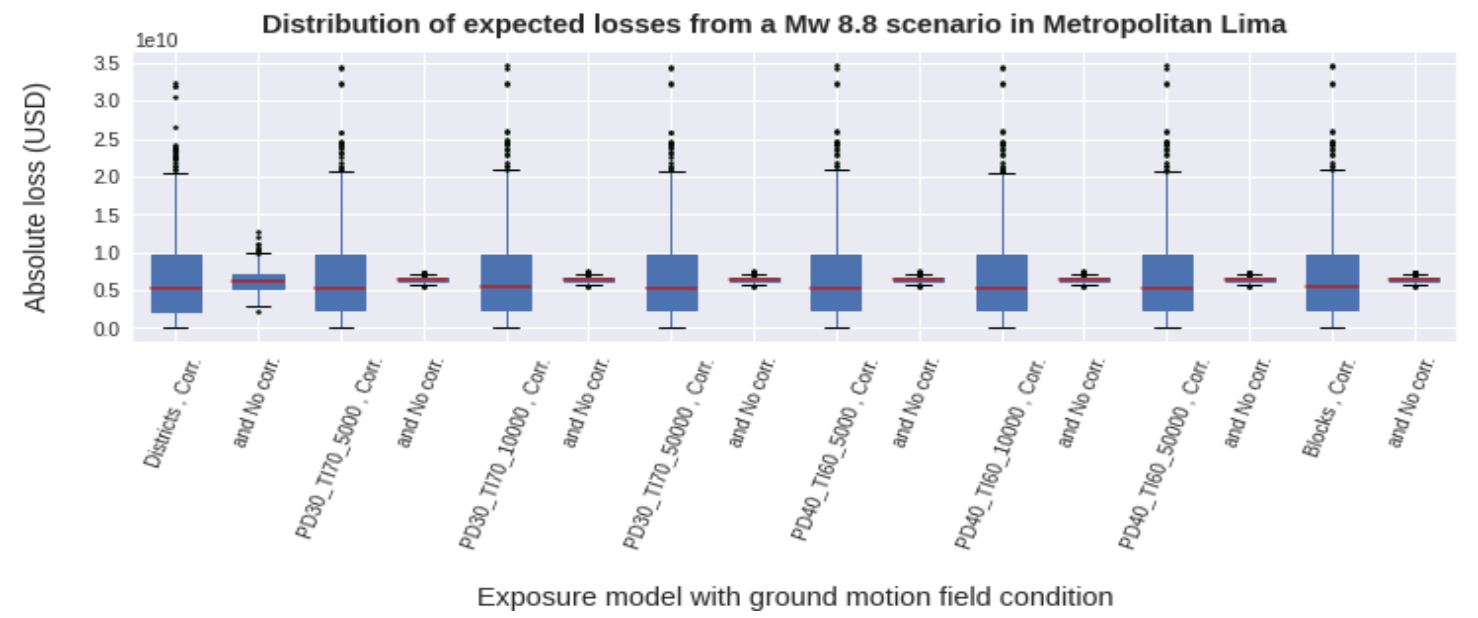

Figure 9. Computed loss distributions from a Mw 8.8 scenario for the residential building stock of Lima classified in terms of the SARA vulnerability classes aggregated into eight geographical entities. Two ground motion field conditions are analysed in every case, namely with the selected cross-correlation model (Corr.) and with uncorrelated ground motion fields (No Corr.).

The financial loss results that we have obtained are similar to the loss distribution estimated by Markhvida et al., (2017) who reported mean loss values $\sim 7$ and maxima $\sim 35$ billion USD. That study investigated the possible losses of the residential building stock of Lima/Callao (aggregated into a regular grid $\left(\sim 1 \mathrm{~km}^{2}\right)$ ) expected from a similar Mw 8.8 scenario. Although the authors employed a different GMPE with respect to the one we have adopted, the ground motion cross-correlation model as well as the set of building classes and fragility functions are the same we have implemented. 
In Figure 10 the spatial distributions of losses for the considered Mw 8.8 scenario are shown for the "La Punta" sector for

415 two selected ground motion realisations. In accordance with Vamvatsikos et al., (2010) and similar to other studies entailing spatial comparison of risk estimates (e.g. Senouci et al., 2018), the loss values are normalized. Although the absolute value in the loss estimates is not affected by the aggregation entities (Figure 9), large differences arise when the normalised losses are actually mapped. It can be noted as for the same realisation, regardless of the use of correlated or uncorrelated ground motions, the seismically vulnerable areas are still identifiable, albeit with considerable differences. The use of cross-correlated ground motion fields results in smoother mappings. However, the component which imposes the largest impact on the loss estimated from scenario earthquakes is the simulation of the seismic process, as remarked in other studies (e.g. Silva, 2016). This further highlights the importance of using quantile analysis in mapping seismic risk estimates for better visualisation and communication of the uncertainties in an inherently stochastic process (Geller, 2015).

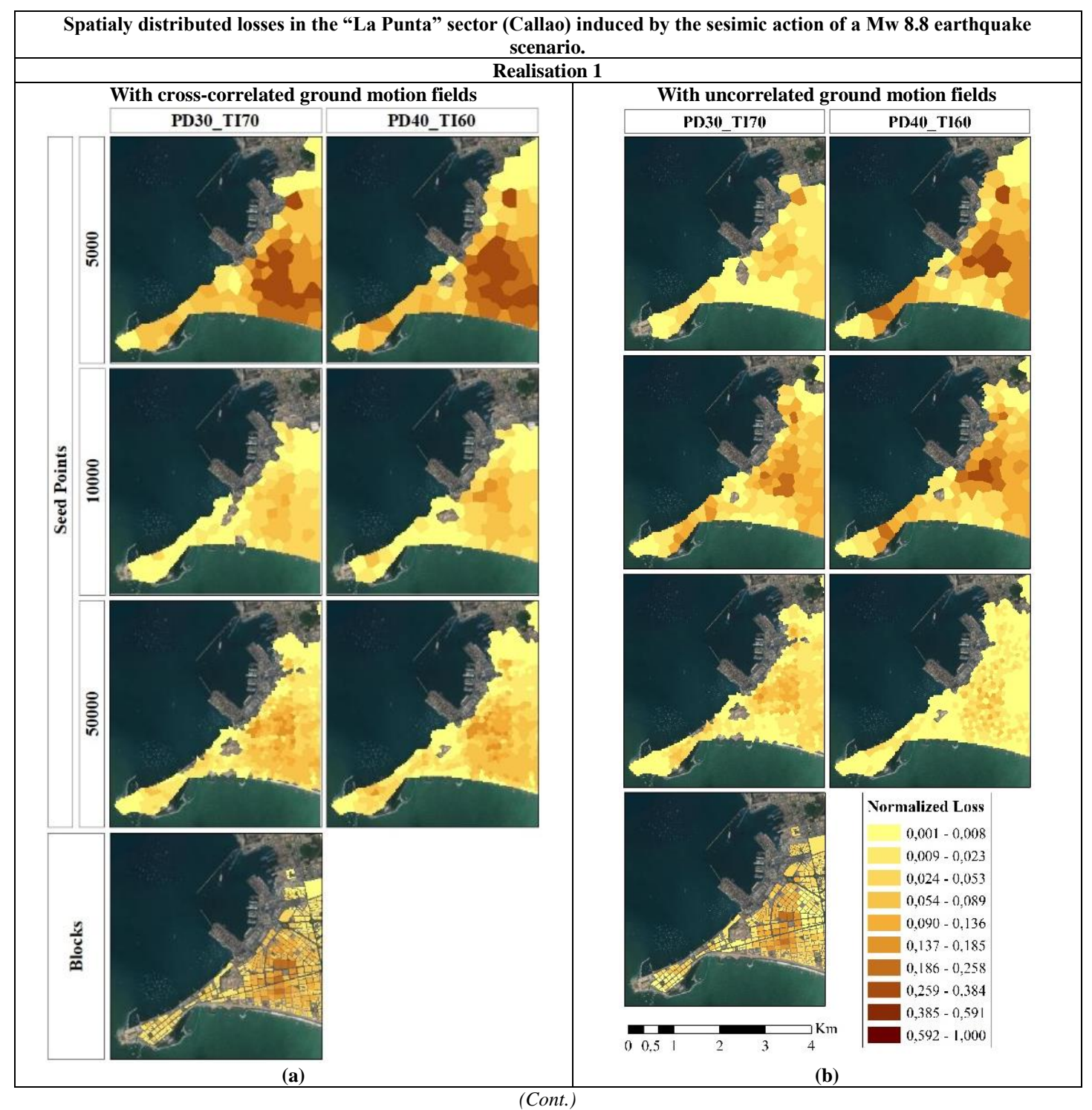




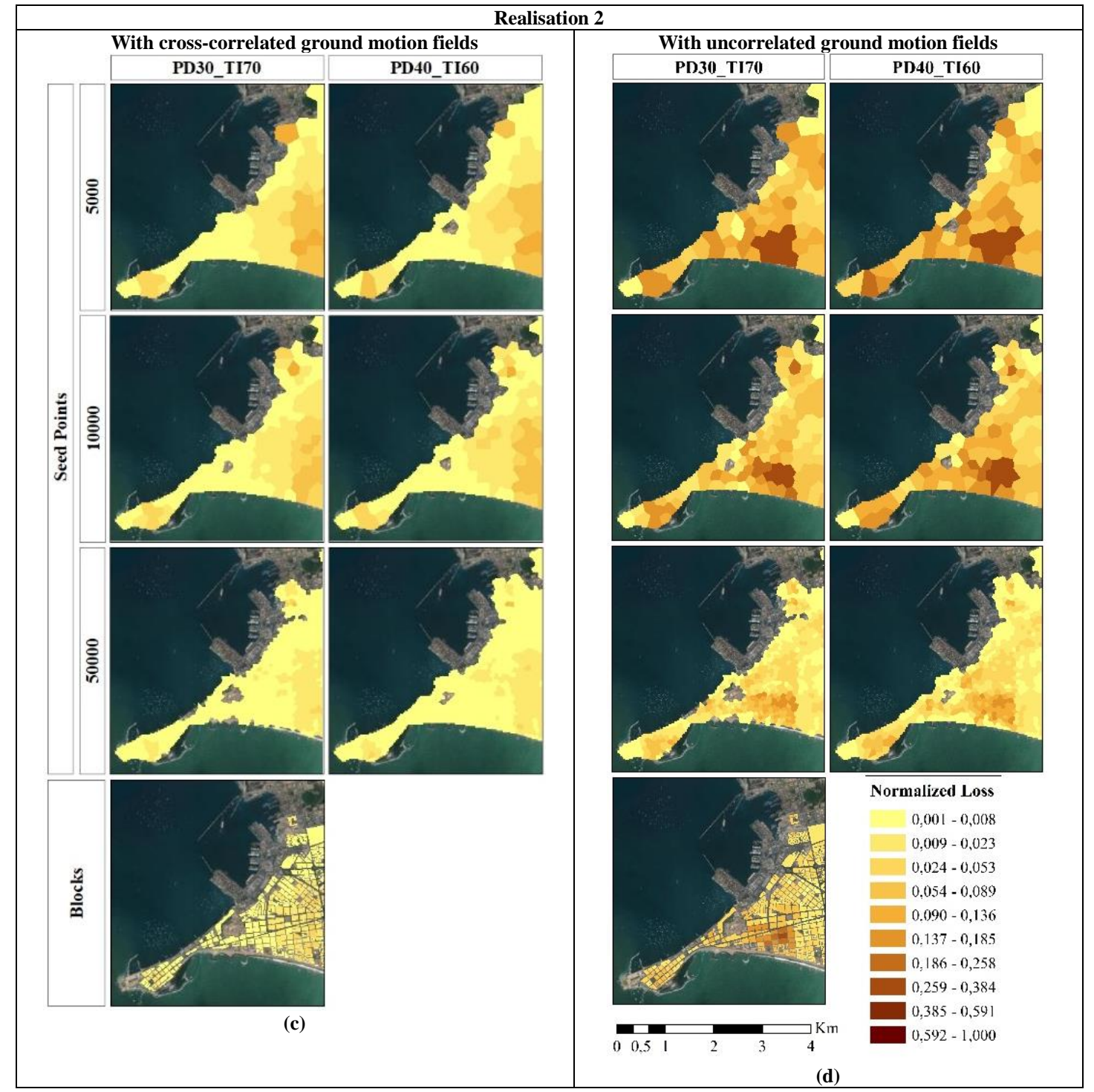

Figure 10. Spatially distributed losses in the "La Punta" sector (Callao) induced by seismic ground-shaking of a Mw 8.8 earthquake scenario. They are mapped over six aggregation areas of the building portfolio classified in terms of the SARA vulnerability classes. This is done for two randomly selected realisations with uncorrelated ground motion fields $(b, d)$ and cross-correlated ground motion fields $(a, c)$ using the Markhvida et al., (2018) model for the periods PGA, 0.3 s and 1.0 s. Map data: (OGoogle Earth 2021.

\subsubsection{Tsunami risk}

To constrain the economical consequence model used in tsunami risk assessment, the inter-scheme conversion matrices depicted in Figure 6 are used to obtain the replacement cost values per building class from the correspondent maximum scoring class in

435 SARA. We have assumed loss ratios 5\%, 15\%, 45\%, 65\%, 85\%, and 100\% for each of the six damage states proposed by Suppasri et al., (2013) and similarly, but starting with 15\%, for the five ones proposed in De Risi et al., (2017). A similar approach has been recently adopted by Antoncecchi et al., (2020). The impact of using more exhaustive approaches (e.g. (Suppasri et al., 2019) is 
worth exploring, but out of the scope of this paper. Both tsunami-vulnerability schemes have been associated with a set of empirical fragility functions with tsunami inundation height in meters as IM. They were derived from the same building damage dataset collected after the great $2011 \mathrm{Mw} 9.1$ Japan earthquake and tsunami with damage state definitions that implicitly accounted for the combined effect of both hazardous events. Thus, despite the extensive use of empirically derived fragility functions from that specific near-field event, care should be taken when using them, not only because they also account for the ground-shaking induced damage, but also because a submarine landslide could have contributed to the tsunami (Tappin et al., 2014). Nevertheless, there is a profound difference in the way the mean intensity values were obtained. Whilst in Suppasri et al., (2013), a linear least squares regression fitting was carried out, in De Risi et al., (2017) a multinomial logistic regression was performed for material-based classes. The latter found very similar regression values to the case when an average simulated flow velocity of $1.84 \mathrm{~ms}^{-1}$ for masonry and wooden buildings classes (predominant in Lima) is integrated into an hybrid fragility model. Making use of these two schemes, we have correspondingly estimated the tsunami-induced losses for the six scenarios and for the seven exposure models. Tsunami loss estimates normalised to the losses by the block-model are presented in Figure 11. Independent of the reference scheme, the two CVT models with the largest number of geocells $(50,000)$ show the closest similarity to the block model (normalized ratio 1). However, for all the CVT models, this ratio dramatically drops for scenarios with lower magnitudes (8.5, 8.6, and 8.7) which can probably be explained by a smaller tsunami footprint and lower IM spatial correlation.
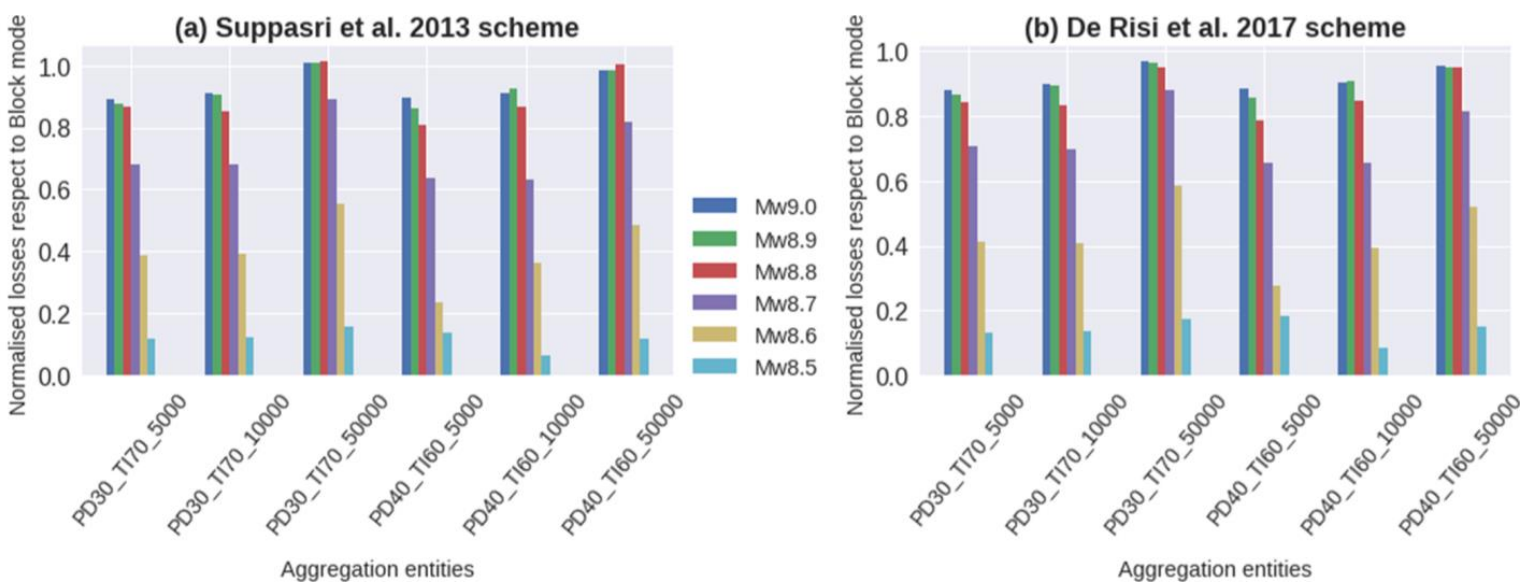

Figure 11. Losses induced by six tsunamis for the six CVT models normalised with respect to the ones at the block level. Tsunami vulnerability has been computed using the set of building classes proposed in (a) Suppasri et al., 2013 and (b) De Risi et al., 2017.

The absolute loss values expected after the six tsunami scenarios are reported in Figure 12 at the block level for the two vulnerability reference schemes. The fragility models of Suppasri et al., (2013) predict larger values with respect to the model proposed by De

Risi et al., (2017) whose functional values were found within the range as if flow velocity was accounted. These findings are in line with the observations of Park et al., (2017); and Song et al., (2017). These studies concluded that flow-depth models predict larger probabilities of complete damage for buildings than models which that addressed tsunami velocity in their derivation.

We have computed the discrepancy in the tsunami loss estimations obtained for each CVT model with respect to the block-based model (Figure 13). This is minimised for the larger magnitudes and higher resolution models (50,000 geocells). This analysis shows that the Suppasri et al., (2013) fragility model leads to slightly larger differences (with respect to the block-based 
model) for the three lower magnitudes, whereas De Risi et al., (2017) does it for the three larger ones. These differences are minimised for the largest resolution model.

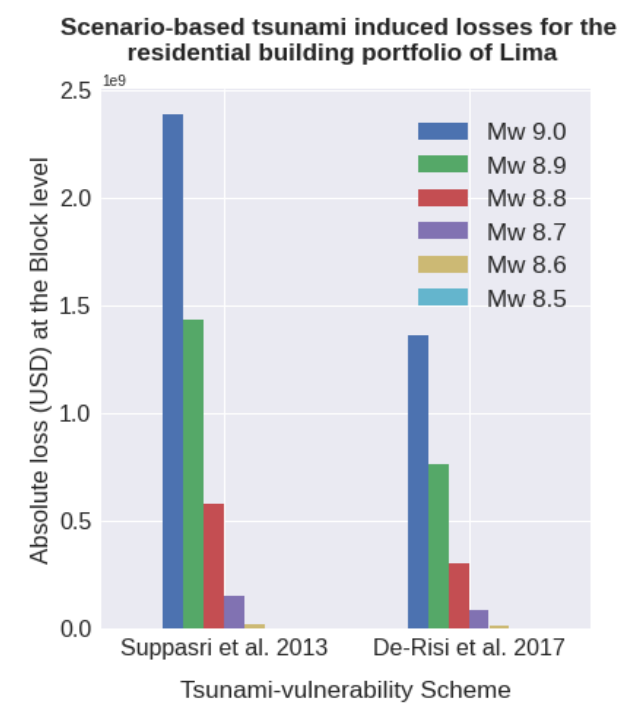

Figure 12. Absolute losses (USD) for six tsunami scenarios for the residential building portfolio of Lima classified in terms of two reference schemes and aggregated at the block-based model.

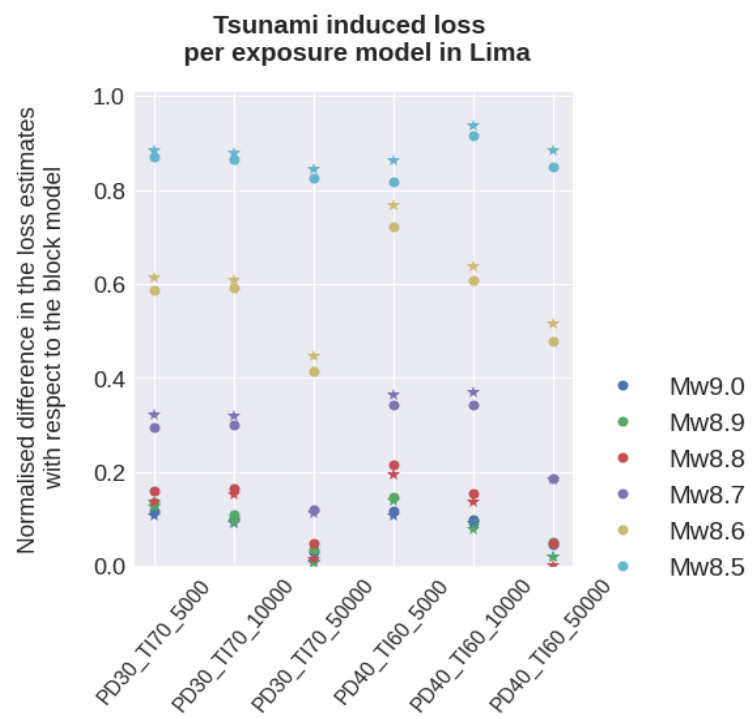

Figure 13. Discrepancy between the tsunami-induced losses between each CVT-based model and the block model for the six scenarios. The values obtained from the Suppasri et al., 2013 and De Risi et al., 2017 schemes are denoted by stars and circles respectively.

Estimates at the block level are $~ 3$ times less efficient (i.e. larger size, in Table 1) compared to the CVT-models with 50,000 geocells for which almost identical results are obtained (Figure 11), and 23 times larger than CVT-models with 5,000 geocells for which overestimations lower than $20 \%$ are expected for the three largest magnitudes (Figure 13). Aggregation entities with lower resolutions lead to overestimations in the tsunami-induced losses. Similar findings were reported in Figueiredo and Martina (2016) in flood risk analysis.

Tsunami loss outcomes for the Mw. 8.8 scenario are mapped and discussed hereafter for the residential building stock in the two areas "La Punta" (Figure 14) and Chorrillos district (Figure 15). Only geocells with loss values larger than zero are colourmapped. Due to the normalised metric used, no significant differences in the tsunami vulnerability mapping induced by the independent building classification schemas are noticeable. The CVT models at the coarser resolutions (first two rows in every figure) show the largest values, and hence overestimations compared to the block level and other finer CVT- models.

Overestimation of losses decreases with the increase of resolution. Due to the adjacency and compactness of the highest resolution CTV model (fourth row), for "La Punta" we identify at least four zones with a comparatively higher tsunami vulnerability. 
(a) Suppasri et al., 2013 scheme

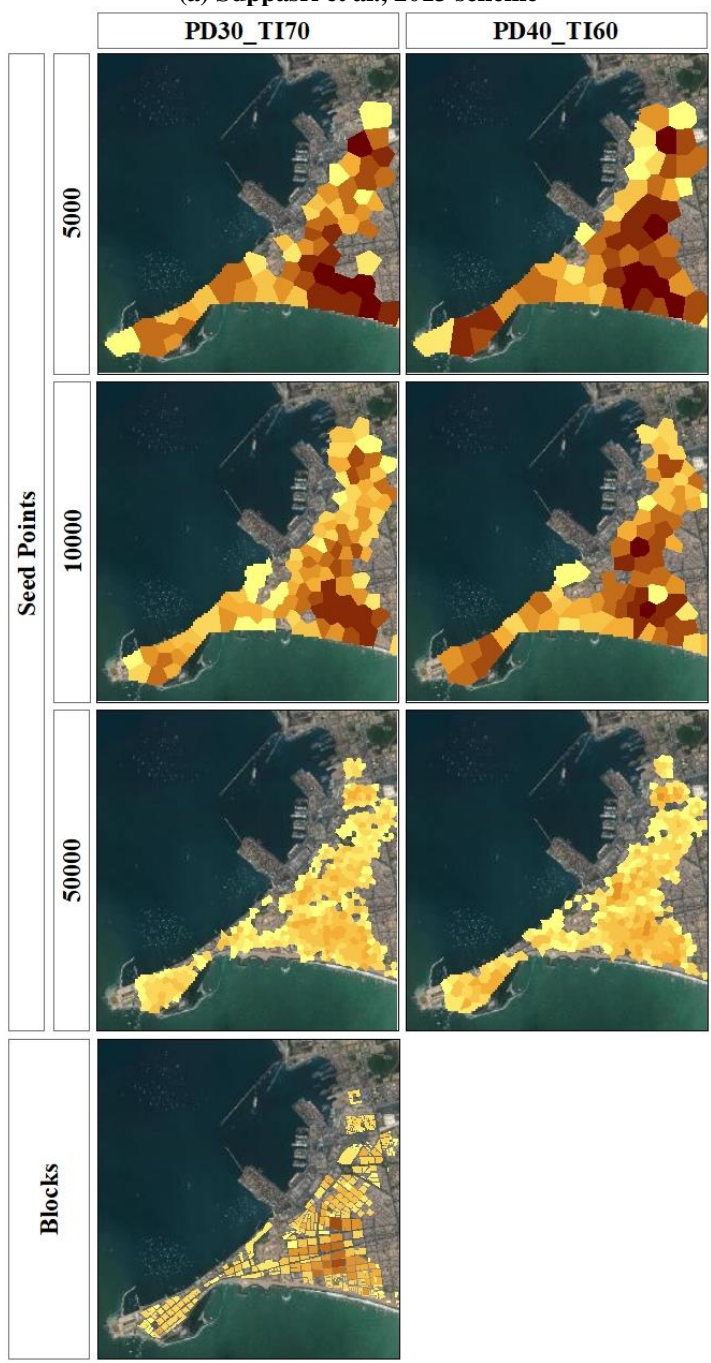

(b) De Risi et al., 2017 scheme
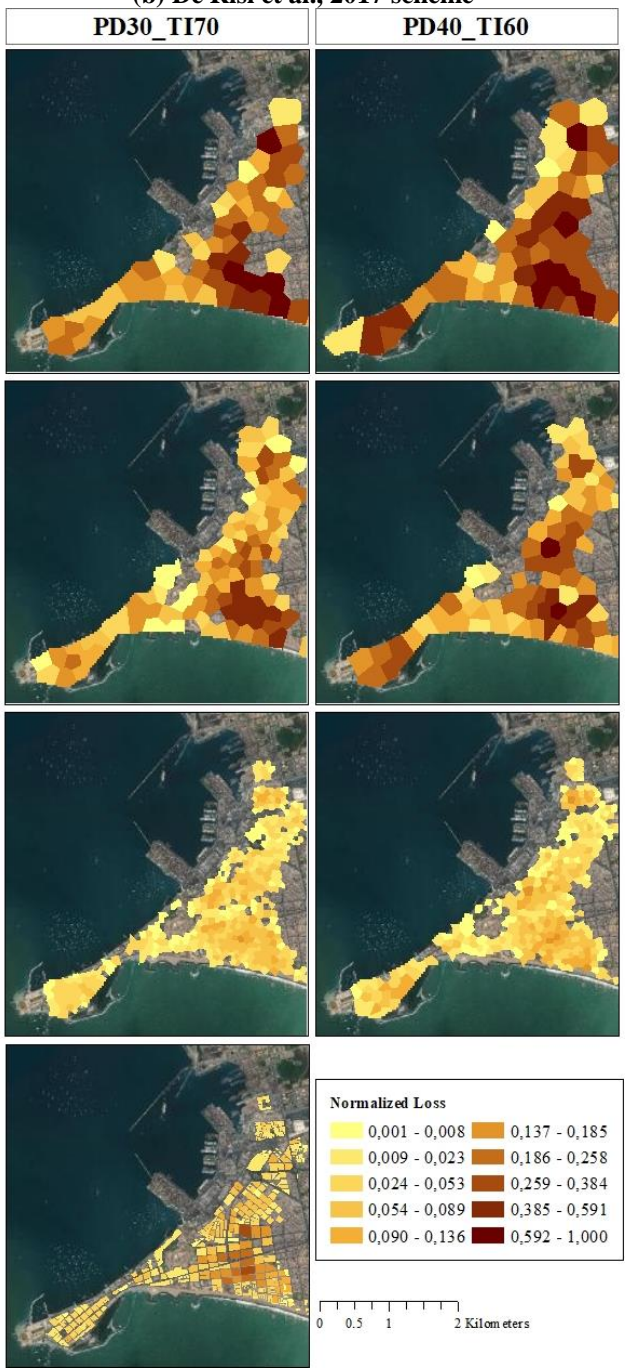

Normalized Loss
$0,001-0,008 \square 0,137-0,185$ $0,009-0,023 \square 0,186-0,258$ $0,024-0,053 \square 0,259-0,384$ $0,054-0,089 \square 0,385-0,591$ $0,090-0,136 \square 0,592-1,000$

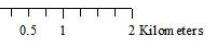

Figure 14. Spatial distribution of tsunami-induced normalized losses (Mw 8.8 scenario) for the La Punta sector (Callao district). Map data: CGoogle Earth 2021.

485 Considering Figure 15, it can be noted that the overall mapped area is increasingly reduced as the resolution of the CVT models increases. This is due to the lack of residential buildings within the three large parcels, namely "Country Club de Villa", "Reserva Laguna de Villa" and "Refugio de Vida Salvaje Pantanos de Villa" that occupy most of the exposed area in the block-based model. These zones represent the largest area values in Figure 8-b. This model assigns the largest loss values in the Chorrillos district to these three large blocks due to the assumption of using a single tsunami intensity as representative of the entire enclosing area.

490 Therefore, if the block polygons are too coarse compared with the hazard footprint and IM spatial correlation, biases in the loss assessment are expected. This is highlighting the importance of hazard-driven entities for exposure spatial aggregation. 
(a) Suppasri et al., 2013 scheme

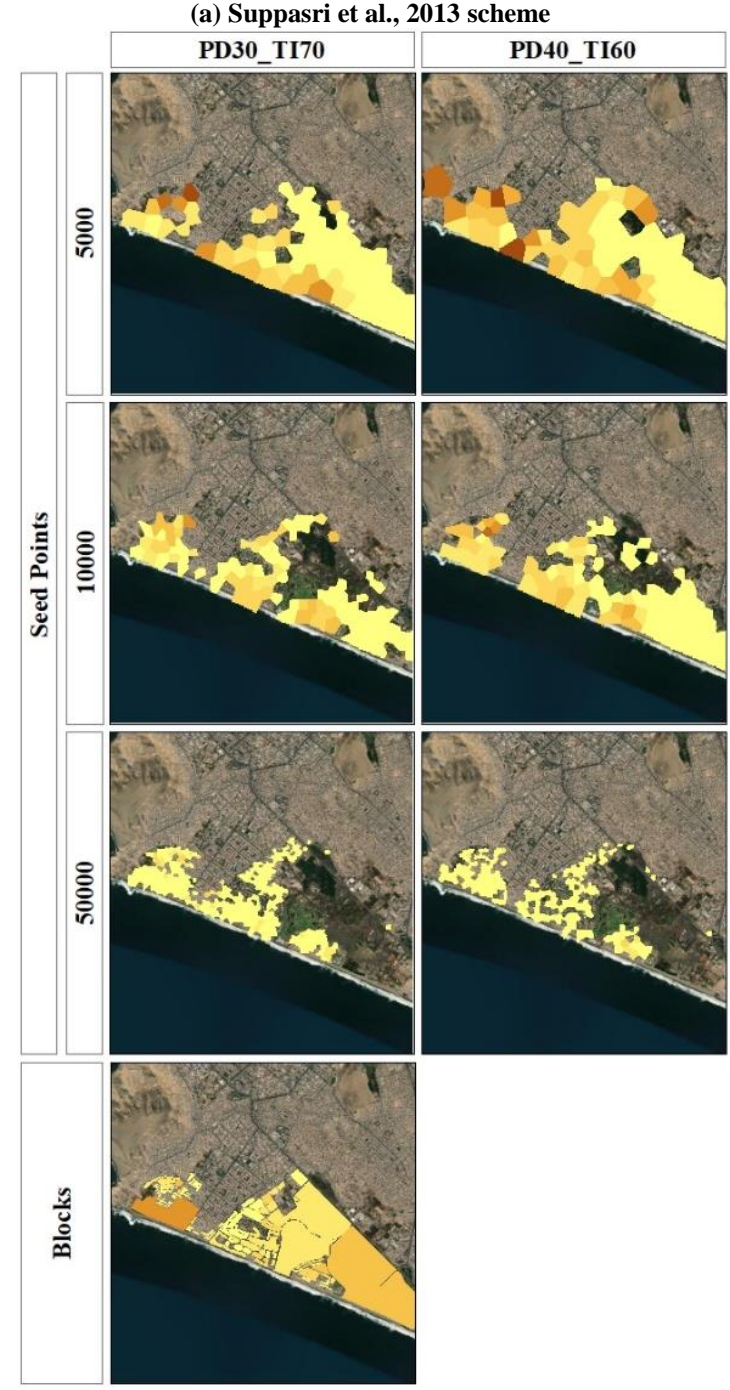

(b) De Risi et al., 2017 scheme

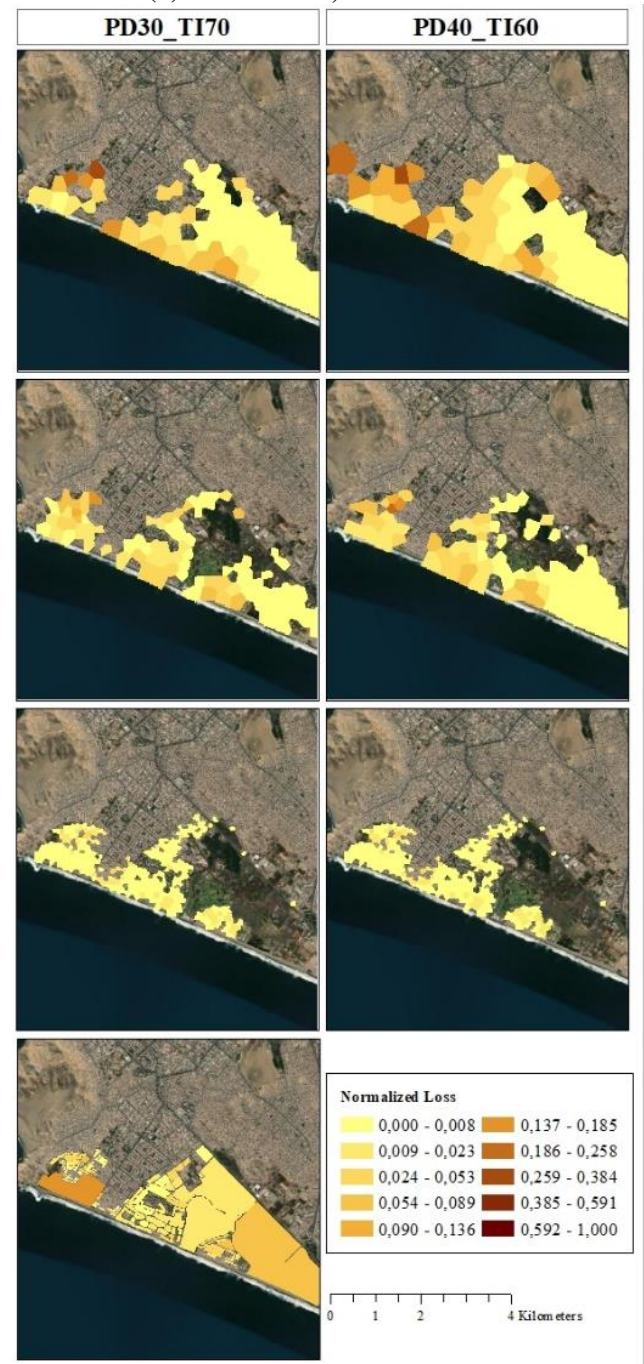

Figure 15. Spatial distribution of tsunami-induced normalized losses (Mw 8.8 scenario) for the Chorrillos district (Lima). Map data: @Google

\subsubsection{Comparison between earthquake and tsunami scenario-based induced losses}

In Figure 16 we compare the absolute losses induced by each hazard scenario onto the building portfolio exposed to both perils (e.g. Mw 9.0 in Figure 4-b). The CVT-based PD30_TI70_5,000 is used to represent the earthquake-induced losses. The latter was

500 compiled for the cases with and without ground motion cross-correlation model, each sampled with 1,000 realisations. Due to the lack of stochastic realisations in the tsunami case, the respective loss distributions were constructed for both reference schemes with the seven values obtained from the various aggregation entities (6 CVT- and 1 block-based models). Despite the fact that the distributions for seismic and tsunami losses have been obtained independently, the median values are nevertheless illustrative for comparative purposes. 


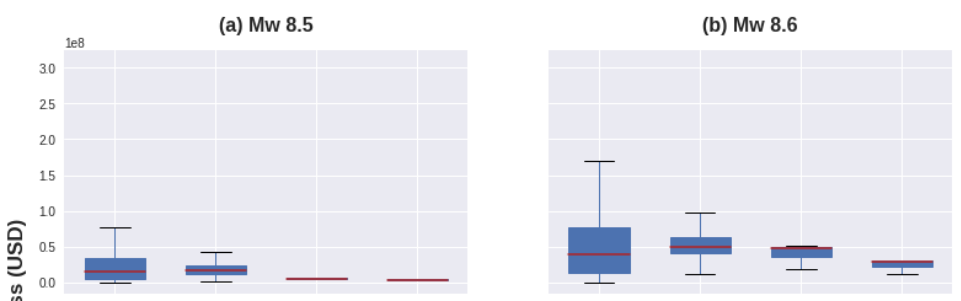

(d) Mw 8.8

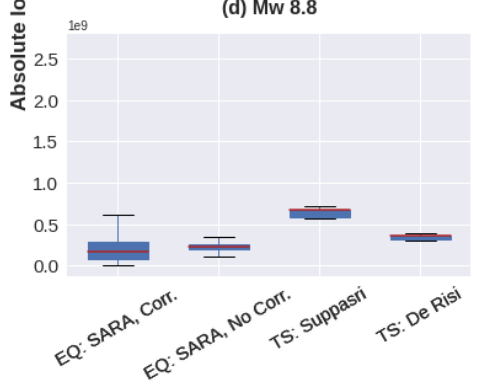

(b) Mw 8.6

(e) Mw 8.9

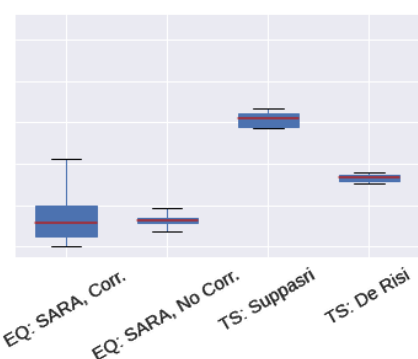

(c) Mw 8.7

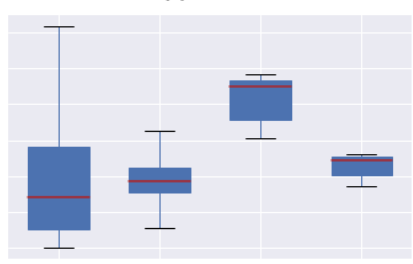

(f) Mw 9.0

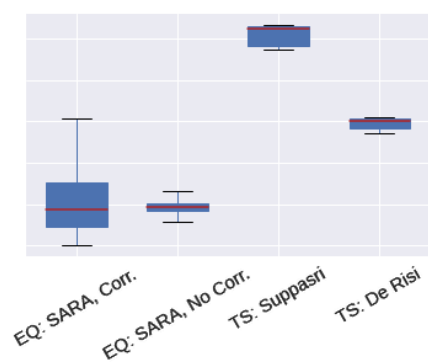

Figure 16. Comparison of the independent earthquake-induced losses (EQ) for two ground motion field conditions (with and without ground motion cross-correlation model) and the tsunami-induced losses (TS) under two tsunami reference schemes for six magnitude scenarios over every common area exposed to both perils.

510

We observe that in our estimations for the commonly exposed area to both perils in Lima, the earthquake event dominates the median losses at lower magnitudes (Mw 8.5, 8.6) whilst the tsunami prevails in the larger ones. The tsunami-induced median losses start to be larger than the earthquake-related ones for the Mw 8.7, although the latter still present high volatility in the extreme values due to the variability in the seismic realisations. From Mw 8.8 on, the tsunami-induced losses are always larger regardless of the tsunami reference scheme implemented. Our findings regarding the role of the earthquake magnitude in the disaggregation of financial loss estimates for every hazard scenario are in line with the results of Goda and De Risi, (2018) obtained for a coastal town in Japan jointly exposed to two decoupled earthquakes and tsunamis risk scenarios (Mw 8.0, 9.0).

\section{4}

\section{Discussion}

CVT-based aggregation entities for building exposure modelling can be further customized. For instance, the underlying focus map can be modified in order to integrate other components such as higher resolution seismic microzonation; spatially explicit distributions of the duration of the expected hazard scenario, key aspect in hydraulic risk assessment (Ward et al., 2020); the spatial presence of certain building taxonomic attributes that may drive the physical vulnerability towards a given hazard (e.g. soft-storey in seismic vulnerability and openings or building foundation in tsunami vulnerability (Alam et al., 2018)); high-resolution DEM (digital elevation model). However, caution should be taken not to double count their contribution if the hazard simulations have already been performed using these input data (e.g. DEM in landslide susceptibility and tsunami inundation) as well as a wise selection of their respective weights in the focus map construction. Furthermore, CVT model generation would benefit from further improvements such as outlining an iterative approach that can seek for a minimum geocell size from a convergence criterion imposed by one or several spatially correlated hazard-IM-lengths.

Several of the limitations in this study could be addressed in further studies. For instance, including the computation of an exhaustive set of stochastic tsunami inundation scenarios (per considered magnitude) for loss assessment, as well as including 
a higher-resolution digital surface model with spatially distributed roughness values once such measurements are available. Physics-based tsunami fragility functions based on intensities more relevant to the building failure mechanisms such as momentum flux (e.g. Macabuag et al., 2016; Attary et al., 2017) would benefit future risk simulations. However, this is subject to their actual availability for the typical Peruvian building classes. More comprehensive adaptations of such as "foreign" fragility models (e.g.

535 Suppasri et al., 2019) in Peru, as well as the need of future development of analytical models for the South American context (e.g. (Medina et al., 2019) would benefit future risk assessment studies for Lima. Another area that would benefit from future research is the differential selection of loss ratios with dependencies on the building classes, as for instance recently investigated by Kalakonas et al., (2020) for seismic risk applications. This might be also relevant for tsunami-induced losses that are strongly influenced by the presence and cost of non-structural building elements. Accordingly, more refined financial tsunami consequence models such as the one proposed by Suppasri et al., (2019) and/ or Triantafyllou et al., (2019) are worth exploring when detailed information about prices and built-up areas at the individual building level are available for the study area. In the presented example case, the tsunami economic consequence model was entirely based on the replacement costs of the SARA model obtained from the inter-scheme conversion matrix. On the one hand, the latter makes that the exposed residential assets classified under various schemes have equivalent replacement costs, and thus, the hazard-dependent risk estimates can be comparable with each other. On the other hand, caution should be taken when interpreting the presented results. Neither the damages induced by debris impacts nor scour, relevant for a clearer tsunami vulnerability assessment (Charvet et al., 2015), are included in our modelling. Moreover, it is worth to mention that larger indirect losses can be expected from buildings with other occupancies (e.g. Chen et al., 2018) that we have not considered herein.

CVT-based models can be beneficial to define efficient, multi-hazard aggregation entities for earthquake and tsunami risk assessment, not only in Lima, but also in other coastal cities exposed to similar hazards. Furthermore, it is worth investigating the usefulness of in mapping cumulative damage and losses in hazard sequences i.e. when a first hazardous event modify the fragility of buildings that are then affected by a successive event.

\section{5}

\section{Conclusions}

The focus map concept formulated by Pittore (2015) has been used to integrate spatially correlated hazard intensity measures (IMs) with exposure proxies (i.e. population density) to spatially identify hot-spot areas where higher values from both distributions are expected. A focus map can then be sampled by a heterogeneous Poisson point process, as proposed by Pittore et al., (2020) in order to generate variable-resolution aggregation entities in the form of a Central Voronoi Tessellations. The proposed method is subject to epistemic uncertainties, namely the selection of weights for pooling of geospatial layers into the focus map and the selection of seeding points that provide initial seeding set and control the overall number of geocells. Through the application of a condition tree, we have selected different sets of these two components to investigate the impact of customised CVT-based geographical entities used to aggregate building portfolios. This is done through independent risk loss estimates per hazard as well as through the reconnaissance of thematic uncertainties in the loss mapping and visualisation.

Variable-resolution CVT-based exposure models proposed in this work have proved their efficiency in integrating largearea building portfolios for combined earthquake and tsunami loss estimations. Several advantages over conventional models based on administrative aggregation entities are:

- CVT-based models provide alternative an approach to aggregate an extensive building portfolio constructed from ancillary data (i.e. population) in the case when existing administrative aggregation areas are not suitable (either not publicly available, 
or too coarse in resolution) for a certain area of interest, as well as to perform scenario-based risk assessments from various hazards.

- We have observed that they correct some bias in the spatial aggregation of buildings due to the smaller, more compact areas in high-resolution CVT geocells with respect to a coarser, block-based cell. This correction is further propagated to the loss estimates due to the higher density of IM values employed by the respective fragility functions during the loss assessment. This is especially observed in areas of the largest concentration of exposed assets located within the hazard footprint area and where local spatial variations of the IM are expected, leading to more accurate estimates.

- They are computationally more efficient than the block-based models in earthquake and tsunami vulnerability assessment. This is advantageous when thousands of stochastic realisations of hazard scenarios are calculated over the aggregation boundaries that are used to model building portfolios.

- They have shown to be beneficial to map loss estimates in continuous space with adjacent and compact geocells. These features allow the spatial identification of zones with similar vulnerability to the hazards considered and within the area of interest. They contribute to a more intuitive visualisation and interpretation of the loss mapping and hence contribute to raising awareness about epistemic and thematic uncertainties in the loss mapping. That is a significant help for decisionmakers in undertaking urban requalification or disaster risk mitigation activities (e.g. Dolce and Di Bucci, 2015).

For the portfolio exposed to both perils in Lima, we have found that the expected median loss values induced by seismic ground-shaking are insensitive to the representation of the exposure model at varying resolutions. Thus, we are confirming the finding reported in Bal et al., (2010) and expanding it to the case when cross-correlated ground motion fields are considered. However, this is contrasting to tsunami loss models, whose differences with respect to a high-resolution model (i.e. block-based) decrease as the resolution of CVT geocells increases. Similarly, these differences are remarkably minimised for incrementally correlated tsunami-intensities from the large magnitude tsunami scenarios (i.e. Mw 8.8, 8.9, 9.0). According to our observations, the adopted tsunami fragility model based on solely flow-depth as IM and linear square fitting (Suppasri et al., 2013) predicts much larger tsunami-induced losses on the residential buildings portfolios in Lima than the model of De Risi et al., (2017) derived through multinomial logistic regression and with similar values as if flow velocity was accounted. For the residential building portfolio exposed to both perils, we have found that the earthquake scenarios dominate the losses at lower magnitudes (Mw 8.5, 8.6) whilst the contribution of tsunami is dominant for the larger magnitude events. Thus, this study invites to realise the comparative relevance of the tsunami risk in extreme future scenarios in Lima, a coastal mega-city whose safety is vital for the overall economy of the country.

Bearing in mind the scope of this study, but also the aforementioned limitations in the discussion section, we are not claiming that the scenario-based economic losses we have presented for the residential building stock of Lima are completely exhaustive. Instead, through the adoption of the condition tree, we have drawn a branched methodological workflow to explore the differential impact of the exposure aggregation models, and the selection of building schemes on the epistemic and thematic uncertainties that are embedded in scenario-based risk applications. As described by Beven et al., (2018), condition trees facilitate the communication of the meaning of the resulting uncertainties while providing a clear audit trail for their analysis that can be reviewed and evaluated by others (e.g. local experts and stakeholders) at a later date. Nevertheless, these aspects are highlighting the importance about keep working on seismic and tsunami fragility models that consider particular construction practices, local hydrodynamics, and remarkably, the relevance of hazard-sound aggregations entities for exposure modelling and loss mapping.

605 Thus, the continuous understanding of those uncertainty sources is contributing to enhance future risk communication, mitigation, and disaster management activities by local decision-makers. 
Code and data availability. The codes and data models used in this paper are available under reasonable request to the author.

Competing interests. The authors declare that they have no conflict of interest. The funders had no role in the design of the study; in the collection,

analyses, or interpretation of data; in the writing of the manuscript; or in the decision to publish the results.

Funding. The authors disclosed receipt of the financial support for the research and publication of this article from the RIESGOS project (Multirisk analysis and information system components for the Andes region), funded by the German Federal Ministry of Education and Research (BMBF) Grant No. 03G0876, as part of the funding programme CLIENT II - International Partnerships for Sustainable Innovations.

615 Acknowledgements. The authors want to express their gratitude to Glendy Linares, Waldor Arevalo and Walter Tapia from the Peruvian Office of National Security and Defence (Ministry of Housing, Construction and Sanitation) for providing the INE, 2017 census geo-dataset. Thanks to Catalina Yepes (GEM) for providing the SARA exposure model and mapping schemes for Lima. Thanks to Kim Knauer (EOMAP) for a unified topography and bathymetry data set for the study region. We thank Sandra Santa-Cruz and Nicola Tarque (PUCP), Miguel Estrada, Diana Calderón, Fernando Lázarez, (CISMID), Luis Ceferino (Princeton University), Mary Chris Suarez (YANAPAY), Alireza Mahdavi (AWI), and

620 Omar Campos (DHN) for the fruitful discussions regarding the seismic and tsunami hazard and risk in Lima during some of the authors' visits to the city. Likewise, we thank Tiziana Rossetto, Dina D'Ayala, Ingrid Charvet, Carmine Galasso, and Juan Palomino (UCL) and Pierre Gehl (BRGM) for the feedback during the 2019 Multi-hazard EPICentre encounter in London. As well as to Heidi Kreibich (GFZ) for the invitation to the 2020-AOGS-EGU NtHazards virtual Seminar, during which we were inspired to continue this study by Anawat Suppasri (Tohoku University). Special thanks to Elisabeth Schöpfer (DLR), Cecilia Nievas, Graeme Weatherill, Henning Lilienkamp, Matthias Rüster, and Jörn

Lauterjung (GFZ) for their valuable advice during the elaboration of this study.

\section{References}

Adriano, B., Mas, E., Koshimura, S., Estrada, M., Jimenez, C., 2014. Scenarios of Earthquake and Tsunami Damage Probability in Callao Region, Peru Using Tsunami Fragility Functions. Journal of Disaster Research 9, 968-975. https://doi.org/10.20965/jdr.2014.p0968

Aguilar, Z., Lazares, F., Alarcon, S., Quispe, S., Uriarte, R., Calderon, D., 2013. Actualización de la Microzonificación Sísmica de la ciudad de Lima. Presented at the International Symposium for CISMID 25th Anniversary 17-18 August, 2012, Lima, Peru.

Aguirre-Ayerbe, I., Martínez Sánchez, J., Aniel-Quiroga, Í., González-Riancho, P., Merino, M., Al-Yahyai, S., González, M., Medina, R., 2018. From tsunami risk assessment to disaster risk reduction - the case of Oman. Natural Hazards and Earth System Sciences 18, 22412260. https://doi.org/10.5194/nhess-18-2241-2018

Alam, M.S., Barbosa, A.R., Scott, M.H., Cox, D.T., van de Lindt, J.W., 2018. Development of Physics-Based Tsunami Fragility Functions Considering Structural Member Failures. Journal of Structural Engineering 144, 04017221. https://doi.org/10.1061/(ASCE)ST.1943541X.0001953

Allen, T.I., Wald, D.J., 2007. Topographic Slope as a Proxy for Seismic Site-Conditions (VS30) and Amplification Around the Globe (Report No. 2007-1357), Open-File Report. https://doi.org/10.3133/ofr20071357

Antoncecchi, I., Ciccone, F., Dialuce, G., Grandi, S., Terlizzeze, F., Di Bucci, D., Dolce, M., Argnani, A., Mercorella, A., Pellegrini, C., Rovere, M., Armigliato, A., Pagnoni, G., Paparo, M.A., Tinti, S., Zaniboni, F., Basili, R., Cavallaro, D., Coltelli, M., Firetto Carlino, M., Lipparini, L., Lorito, S., Maesano, F.E., Romano, F., Scarfî, L., Tiberti, M.M., Volpe, M., Fedorik, J., Toscani, G., Borzi, B., Faravelli, M., Bozzoni, F., Pascale, V., Quaroni, D., Germagnoli, F., Belliazzi, S., Del Zoppo, M., Di Ludovico, M., Lignola, G.P., Prota, A., 2020. Progetto SPOT - Sismicità Potenzialmente Innescabile Offshore e Tsunami: Report integrato di fine progetto. 1. Ministero dello Sviluppo Economico. https://doi.org/10.5281/zenodo.3732887

645 Attary, N., van de Lindt, J.W., Unnikrishnan, V.U., Barbosa, A.R., Cox, D.T., 2017. Methodology for Development of Physics-Based Tsunami Fragilities. Journal of Structural Engineering 143, 04016223. https://doi.org/10.1061/(ASCE)ST.1943-541X.0001715

Bal, I.E., Bommer, J.J., Stafford, P.J., Crowley, H., Pinho, R., 2010. The Influence of Geographical Resolution of Urban Exposure Data in an Earthquake Loss Model for Istanbul. Earthquake Spectra 26, 619-634. https://doi.org/10.1193/1.3459127

Bazzurro, P., Luco, N., 2005. Accounting for uncertainty and correlation in earthquake loss estimation, in: Proceedings of the Nineth International

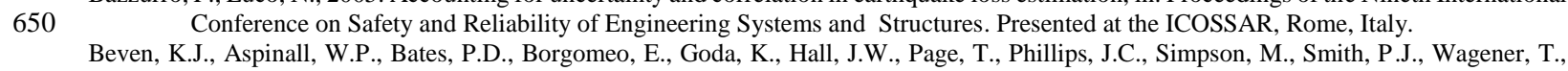
Watson, M., 2018. Epistemic uncertainties and natural hazard risk assessment - Part 2: What should constitute good practice? Natural Hazards and Earth System Sciences 18, 2769-2783. https://doi.org/10.5194/nhess-18-2769-2018

Birkmann, J., Sauter Holger, Jamshed Ali, Sorg Linda, Fleischhauer Mark, Sandholz Simone, Wannewitz Mia, Greiving Stefan, Bueter Bjoern, Schneider Melanie, Garschagen Matthias, 2020. Strengthening risk-informed decision-making: scenarios for human vulnerability and exposure to extreme events. Disaster Prevention and Management: An International Journal 29, 663-679. 
https://doi.org/10.1108/DPM-05-2020-0147

Bozzoni, F., Bonì, R., Conca, D., Lai, C.G., Zuccolo, E., Meisina, C., 2020. Megazonation of earthquake-induced soil liquefaction hazard in continental Europe. Bulletin of Earthquake Engineering. https://doi.org/10.1007/s10518-020-01008-6

660 Bozzoni, F., Bonì, R., Conca, D., Meisina, C., Lai, C.G., Zuccolo, E., 2021. A Geospatial Approach for Mapping the Earthquake-Induced Liquefaction Risk at the European Scale. Geosciences 11. https://doi.org/10.3390/geosciences11010032

Ceferino, L., Kiremidjian, A., Deierlein, G., 2018a. Probabilistic Model for Regional Multiseverity Casualty Estimation due to Building Damage Following an Earthquake. ASCE-ASME Journal of Risk and Uncertainty in Engineering Systems, Part A: Civil Engineering 4, 04018023. https://doi.org/10.1061/AJRUA6.0000972

665 Ceferino, L., Kiremidjian, A., Deierlein, G., 2018b. Regional Multiseverity Casualty Estimation Due to Building Damage following a Mw 8.8 Earthquake Scenario in Lima, Peru. Earthquake Spectra 34, 1739-1761. https://doi.org/10.1193/080617EQS154M

Charvet, I., Macabuag, J., Rossetto, T., 2017. Estimating Tsunami-Induced Building Damage through Fragility Functions: Critical Review and Research Needs. Frontiers in Built Environment 3, 36. https://doi.org/10.3389/fbuil.2017.00036

Charvet, I., Suppasri, A., Kimura, H., Sugawara, D., Imamura, F., 2015. A multivariate generalized linear tsunami fragility model for Kesennuma City based on maximum flow depths, velocities and debris impact, with evaluation of predictive accuracy. Natural Hazards 79, 2073 2099. https://doi.org/10.1007/s11069-015-1947-8

Chen, K., McAneney, J., Blong, R., Leigh, R., Hunter, L., Magill, C., 2004. Defining area at risk and its effect in catastrophe loss estimation: a dasymetric mapping approach. Applied Geography 24, 97-117. https://doi.org/10.1016/j.apgeog.2004.03.005

Chen, Yunguang, Park, H., Chen, Yong, Corcoran, P., Cox, D., Reimer, J.J., Weber, B., 2018. Integrated Engineering-Economic Model for the Assessment of Regional Economic Vulnerability to Tsunamis. Natural Hazards Review 19, 04018018. https://doi.org/10.1061/(ASCE)NH.1527-6996.0000307

CIESIN, 2018. Documentation for the Gridded Population of theWorld, Version 4 (GPWv4), Revision 11 Data Sets, [WWW Document]. NASA Socioeconomic Data And Applications Center (SEDAC) Palisades, NY, USA. URL htps://doi.org/10.7927/H45Q4T5F

Cox, D.R., Isham, V., 1980. Point processes. Chapman and Hall, London, New York.

680 Dabbeek, J., Silva, V., 2019. Modeling the residential building stock in the Middle East for multi-hazard risk assessment. Natural Hazards 100, $781-810$.

Dabbeek, J., Silva, V., Galasso, C., Smith, A., 2020. Probabilistic earthquake and flood loss assessment in the Middle East. International Journal of Disaster Risk Reduction 49, 101662. https://doi.org/10.1016/j.ijdrr.2020.101662

Daniell, J.E., Schaefer, A.M., Wenzel, F., 2017. Losses Associated with Secondary Effects in Earthquakes. Frontiers in Built Environment 3, 30. https://doi.org/10.3389/fbuil.2017.00030

De Risi, R., Goda, K., Yasuda, T., Mori, N., 2017. Is flow velocity important in tsunami empirical fragility modeling? Earth-Science Reviews 166, 64-82. https://doi.org/10.1016/j.earscirev.2016.12.015

de Ruiter, M.C., de Bruijn, J.A., Englhardt, J., Daniell, J.E., de Moel, H., Ward, P.J., 2021. The Asynergies of Structural Disaster Risk Reduction Measures: Comparing Floods and Earthquakes. Earth's Future 9, e2020EF001531. https://doi.org/10.1029/2020EF001531

690 Dilley, M., 2005. Natural disaster hotspots a global risk analysis, Washington, D.C. World Bank.

Dolce, M., Di Bucci, D., 2015. Chapter 18 - Risk Management: Roles and Responsibilities in the Decision-making Process, in: Wyss, M., Peppoloni, S. (Eds.), Geoethics. Elsevier, Oxford, pp. 211-221. https://doi.org/10.1016/B978-0-12-799935-7.00018-6

Dorbath, L., Cisternas, A., Dorbath, C., 1990. Assessment of the size of large and great historical earthquakes in Peru. Bulletin of the Seismological Society of America 80, 551-576.

695 Douglas, J., 2007. Physical vulnerability modelling in natural hazard risk assessment. Natural Hazards and Earth System Sciences 7, $283-288$. https://doi.org/10.5194/nhess-7-283-2007

Dunand, F., Gueguen, P., 2012. Comparison between seismic and domestic risk in moderate seismic hazard prone region: the Grenoble City (France) test site. Natural Hazards and Earth System Sciences 12, 511-526. https://doi.org/10.5194/nhess-12-511-2012

Erdik, M., Fahjan, Y., 2008. Damage scenarios and damage evaluation. Assess Manag Earthq Risk. Netherlands: Springer; 2006. $213-37$.

700 Esposito, S., Iervolino, I., 2012. Spatial Correlation of Spectral Acceleration in European Data. Bulletin of the Seismological Society of America $102,2781-2788$.

Fäh, D., Kind, F., Lang, K., Giardini, D., 2001. Earthquake scenarios for the city of Basel. Soil Dynamics and Earthquake Engineering 21, 405413. https://doi.org/10.1016/S0267-7261(01)00023-9

FEMA, 2003. Multi-hazard loss estimation methodology. Federal Emergency Management Agency, Washington.

705 Figueiredo, R., Martina, M., 2016. Using open building data in the development of exposure data sets for catastrophe risk modelling. Natural Hazards and Earth System Sciences 16, 417-429. https://doi.org/10.5194/nhess-16-417-2016

Figueiredo, R., Schröter, K., Weiss-Motz, A., Martina, M.L.V., Kreibich, H., 2018. Multi-model ensembles for assessment of flood losses and associated uncertainty. Natural Hazards and Earth System Sciences 18, 1297-1314. https://doi.org/10.5194/nhess-18-1297-2018

710 Frolova, N.I., Larionov, V.I., Bonnin, J., Sushchev, S.P., Ugarov, A.N., Kozlov, M.A., 2017 -
levels. Natural Hazards 88, 43-62. https://doi.org/10.1007/s11069-016-2654-9

Geller, R.J., 2015. Chapter 22 - Geoethics, Risk-Communication, and Scientific Issues in Earthquake Science, in: Wyss, M., Peppoloni, S. (Eds.), Geoethics. Elsevier, Oxford, pp. 263-272. https://doi.org/10.1016/B978-0-12-799935-7.00022-8

GEM, 2014. Report on the SARA Exposure and Vulnerability Workshop in Medellin, Colombia (Report produced in the context of the GEM South America integrated Risk Assessment (SARA) project No. Version 1.0-May 2014).

715 Gill, J.C., Malamud, B.D., 2014. Reviewing and visualizing the interactions of natural hazards. Reviews of Geophysics 52, 680-722. https://doi.org/10.1002/2013RG000445

Goda, K., De Risi, R., 2018. Multi-hazard loss estimation for shaking and tsunami using stochastic rupture sources. International Journal of Disaster Risk Reduction 28, 539-554. https://doi.org/10.1016/j.ijdrr.2018.01.002

Goda, K., Mai, P.M., Yasuda, T., Mori, N., 2014. Sensitivity of tsunami wave profiles and inundation simulations to earthquake slip and fault geometry for the 2011 Tohoku earthquake. Earth, Planets and Space 66, 105. https://doi.org/10.1186/1880-5981-66-105

Goda, K., Risi, R.D., Luca, F.D., Muhammad, A., Yasuda, T., Mori, N., 2021. Multi-hazard earthquake-tsunami loss estimation of Kuroshio Town, Kochi Prefecture, Japan considering the Nankai-Tonankai megathrust rupture scenarios. International Journal of Disaster Risk Reduction 54, 102050. https://doi.org/10.1016/j.ijdrr.2021.102050 
Goda, K., Rossetto, T., Mori, N., Tesfamariam, S., 2018. Editorial: Mega Quakes: Cascading Earthquake Hazards and Compounding Risks. Frontiers in Built Environment 4, 8. https://doi.org/10.3389/fbuil.2018.00008

Goda, K., Song, J., 2016. Uncertainty modeling and visualization for tsunami hazard and risk mapping: a case study for the 2011 Tohoku earthquake. Stochastic Environmental Research and Risk Assessment 30, 2271-2285. https://doi.org/10.1007/s00477-015-1146-x

Goda, K., Yasuda, T., Mori, N., Mai, P.M., 2015. Variability of tsunami inundation footprints considering stochastic scenarios based on a single rupture model: Application to the 2011 Tohoku earthquake. Journal of Geophysical Research: Oceans 120, 4552-4575. https://doi.org/10.1002/2014JC010626

Goda, K., Yasuda, T., Mori, N., Muhammad, A., De Risi, R., De Luca, F., 2020. Uncertainty quantification of tsunami inundation in Kuroshio, Kochi Prefecture, Japan, using the Nankai-Tonankai megathrust rupture scenarios. Natural Hazards and Earth System Sciences 20, 3039-3056. https://doi.org/10.5194/nhess-20-3039-2020

Gomez-Zapata, J.C., Pittore, M., Cotton, F., Lilienkamp, H., Simantini, S., Aguirre, P., Hernan, S.M., 2021. Epistemic uncertainty of probabilistic building exposure compositions in scenario-based earthquake loss models. Bulletin of Earthquake Engineering Preprint. https://doi.org/10.21203/rs.3.rs-178120/v1

Harig, S., Chaeroni, Pranowo, W.S., Behrens, J., 2008. Tsunami simulations on several scales. Ocean Dynamics 58, 429-440. https://doi.org/10.1007/s10236-008-0162-5

Harig, S., Immerz, A., Weniza, Griffin, J., Weber, B., Babeyko, A., Rakowsky, N., Hartanto, D., Nurokhim, A., Handayani, T., Weber, R., 2020. The Tsunami Scenario Database of the Indonesia Tsunami Early Warning System (InaTEWS): Evolution of the Coverage and the Involved Modeling Approaches. Pure and Applied Geophysics 177, 1379-1401. https://doi.org/10.1007/s00024-019-02305-1

INE, 2017. Censos Nacionales 2017. Instituto Nacional de Estadistica e Informatica (INEI; Institute of Statistic and Informatics), Lima, Peru.

Jimenez, C., Moggiano, N., Mas, E., Adriano, B., Koshimura, S., Fujii, Y., Yanagisawa, and H., 2013. Seismic Source of 1746 Callao Earthquake from Tsunami Numerical Modeling. Journal of Disaster Research 8, 266-273. https://doi.org/10.20965/jdr.2013.p0266

745 Kaiser, G., Scheele, L., Kortenhaus, A., Løvholt, F., Römer, H., Leschka, S., 2011. The influence of land cover roughness on the results of high resolution tsunami inundation modeling. Natural Hazards and Earth System Sciences 11, 2521-2540. https://doi.org/10.5194/nhess$11-2521-2011$

Kajiura, K., 1972. The directivity of energy radiation of the tsunami generated in the vicinity of a continental shelf. Journal of Oceanography 28 , 260-277. https://doi.org/10.1007/BF02109296

750 Kalakonas, P., Silva, V., Mouyiannou, A., Rao, A., 2020. Exploring the impact of epistemic uncertainty on a regional probabilistic seismic risk assessment model. Natural Hazards. https://doi.org/10.1007/s11069-020-04201-7

Kappos, A.J., Panagopoulos, G., Penelis, G.G., 2008. Development of a seismic damage and loss scenario for contemporary and historical buildings in Thessaloniki, Greece. Soil Dynamics and Earthquake Engineering 28, 836-850. https://doi.org/10.1016/j.soildyn.2007.10.017

755 Kohrangi, M., Bazzurro, P., Vamvatsikos, D., 2021. Seismic risk and loss estimation for the building stock in Isfahan: part II—hazard analysis and risk assessment. Bulletin of Earthquake Engineering. https://doi.org/10.1007/s10518-020-01037-1

Koshimura, S., Oie, T., Yanagisawa, H., Imamura, F., 2009. Developing Fragility Functions for Tsunami Damage Estimation Using Numerical Model and Post-Tsunami Data from Banda Aceh, Indonesia. Coastal Engineering Journal 51, $243-273$. https://doi.org/10.1142/S0578563409002004

760 Kulikov, E.A., Rabinovich, A.B., Thomson, R.E., 2005. Estimation of Tsunami Risk for the Coasts of Peru and Northern Chile. Natural Hazards 35, 185-209. https://doi.org/10.1007/s11069-004-4809-3

Levi, T., Salamon, A., Bausch, D., Rozelle, J., Cutrell, A., Hoyland, S., Hamiel, Y., Katz, O., Calvo, R., Gvirtzman, Z., Ackerman, B., Gavrieli, I., 2018. Earthquake scenario in a national drill, the case of "Turning Point 6", 2012, Israel. Natural Hazards 92, 113-132. https://doi.org/10.1007/s11069-018-3194-2

765 Lloyd, S., 1982. Least squares quantization in PCM. IEEE Transactions on Information Theory 28, 129-137. https://doi.org/10.1109/TIT.1982.1056489

Løvholt, F., Glimsdal, S., Harbitz, C.B., Horspool, N., Smebye, H., Bono, A. de, Nadim, F., 2014. Global tsunami hazard and exposure due to large co-seismic slip. International Journal of Disaster Risk Reduction 10, 406-418. https://doi.org/10.1016/j.ijdrr.2014.04.003

Lovon, H., Tarque, N., Silva, V., Yepes-Estrada, C., 2018. Development of Fragility Curves for Confined Masonry Buildings in Lima, Peru. Earthquake Spectra 34, 1339-1361. https://doi.org/10.1193/090517EQS174M

Lynett, P., 2016. Precise Prediction of Coastal and Overland Flow Dynamics: A Grand Challenge or a Fool's Errand. Journal of disaster research $11,615-623$

Macabuag, J., Rossetto, T., Ioannou, I., Suppasri, A., Sugawara, D., Adriano, B., Imamura, F., Eames, I., Koshimura, S., 2016. A proposed methodology for deriving tsunami fragility functions for buildings using optimum intensity measures. Natural Hazards $84,1257-1285$. https://doi.org/10.1007/s11069-016-2485-8

Markhvida, M., Ceferino, L., Baker, J.W., 2018. Modeling spatially correlated spectral accelerations at multiple periods using principal component analysis and geostatistics. Earthquake Engineering \& Structural Dynamics 47, 1107-1123. https://doi.org/10.1002/eqe.3007

Markhvida, M., Ceferino, L., Baker, J.W., 2017. Effect of ground motion correlation on regional seismic lossestimation: application to Lima, Peru using across-correlated principal component analysis model, in: SBN 978-3-903024-28-1. Presented at the Safety, Reliability, Risk, Resilience and Sustainability of Structures and Infrastructure. 12th Int. Conf. on Structural Safety and Reliability, Christian Bucher, Bruce R. Ellingwood, Dan M. Frangopol (Editors), Vienna, Austria.

Martins, L., Silva, V., 2020. Development of a fragility and vulnerability model for global seismic risk analyses. Bulletin of Earthquake Engineering. https://doi.org/10.1007/s10518-020-00885-1

785 Mas, E., Adriano, B., Pulido, N., Jimenez, C., Koshimura, S., 2014. Simulation of Tsunami Inundation in Central Peru from Future Megathrust Earthquake Scenarios. Journal of Disaster Research 9, 961-967. https://doi.org/10.20965/jdr.2014.p0961

Matsuoka, M., Miura, H., Midorikawa, S., Estrada, M., 2013. Extraction of Urban Information for Seismic Hazard and Risk Assessment in Lima, Peru Using Satellite Imagery. Journal of disaster research 8, 328-345.

Medina, S., Lizarazo-Marriaga, J., Estrada, M., Koshimura, S., Mas, E., Adriano, B., 2019. Tsunami analytical fragility curves for the Colombian Pacific coast: A reinforced concrete building example. Engineering Structures 196, 109309. 
https://doi.org/10.1016/j.engstruct.2019.109309

Merz, B., Kuhlicke, C., Kunz, M., Pittore, M., Babeyko, A., Bresch, D.N., Domeisen, D.I.V., Feser, F., Koszalka, I., Kreibich, H., Pantillon, F., Parolai, S., Pinto, J.G., Punge, H.J., Rivalta, E., Schröter, K., Strehlow, K., Weisse, R., Wurpts, A., 2020. Impact Forecasting to Support Emergency Management of Natural Hazards. Reviews of Geophysics 58, e2020RG000704. https://doi.org/10.1029/2020RG000704

Miyashita, T., Mori, N., Goda, K., 2020. Uncertainty of probabilistic tsunami hazard assessment of Zihuatanejo (Mexico) due to the representation of tsunami variability. Coastal Engineering Journal 62, 413-428. https://doi.org/10.1080/21664250.2020.1780676

Montalva, G.A., Bastías, N., Rodriguez-Marek, A., 2017. Ground-Motion Prediction Equation for the Chilean Subduction Zone. The Bulletin of the Seismological Society of America 107, 901-911. https://doi.org/10.1785/0120160221

Muis, S., Verlaan, M., Winsemius, H.C., Aerts, J.C.J.H., Ward, P.J., 2016. A global reanalysis of storm surges and extreme sea levels. Nature Communications 7, 11969. https://doi.org/10.1038/ncomms11969

Negulescu, C., Benaïchouche, A., Lemoine, A., Le Roy, S., Pedreros, R., 2020. Adjustability of exposed elements by updating their capacity for resistance after a damaging event: application to an earthquake-tsunami cascade scenario. Natural Hazards 104, 753-793. https://doi.org/10.1007/s11069-020-04189-0

Omira, R., Baptista, M.A., Matias, L., Miranda, J.M., Catita, C., Carrilho, F., Toto, E., 2009. Design of a Sea-level Tsunami Detection Network for the Gulf of Cadiz. Natural Hazards and Earth System Sciences 9, 1327-1338. https://doi.org/10.5194/nhess-9-1327-2009

Ordaz, M., Salgado-Gálvez Mario Andrés, Huerta Benjamín, Rodríguez Juan Carlos, Avelar Carlos, 2019. Considering the impacts of simultaneous perils: The challenges of integrating earthquake and tsunamigenic risk. Disaster Prevention and Management: An International Journal 28, 823-837. https://doi.org/10.1108/DPM-09-2019-0295

Pagani, M., Monelli, D., Weatherill, G., Danciu, L., Crowley, H., Silva, V., Henshaw, P., Butler, L., Nastasi, M., Panzeri, L., Simionato, M., Vigano, D., 2014. OpenQuake Engine: An Open Hazard (and Risk) Software for the Global Earthquake Model. Seismological Research Letters 85, 692-702. https://doi.org/10.1785/0220130087

Pang, A., 2008. Visualizing Uncertainty in Natural Hazards, in: Bostrom, A., French, S., Gottlieb, S. (Eds.), Risk Assessment, Modeling and Decision Support: Strategic Directions. Springer Berlin Heidelberg, Berlin, Heidelberg, pp. 261-294. https://doi.org/10.1007/978-3540-71158-2_12

815 Papathoma, M., Dominey-Howes, D., 2003. Tsunami vulnerability assessment and its implications for coastal hazard analysis and disaster management planning, Gulf of Corinth, Greece. Natural Hazards and Earth System Sciences 3, 733-747. https://doi.org/10.5194/nhess3-733-2003

Park, H., Alam, M.S., Cox, D.T., Barbosa, A.R., Lindt, J.W. van de, 2019. Probabilistic seismic and tsunami damage analysis (PSTDA) of the Cascadia Subduction Zone applied to Seaside, Oregon. International Journal of Disaster Risk Reduction 35, 101076. https://doi.org/10.1016/j.ijdrr.2019.101076

Park, H., Cox, D.T., Barbosa, A.R., 2017. Comparison of inundation depth and momentum flux based fragilities for probabilistic tsunami damage assessment and uncertainty analysis. Coastal Engineering 122, 10-26. https://doi.org/10.1016/j.coastaleng.2017.01.008

Petersen, M.D., Harmsen, S.C., Jaiswal, K.S., Rukstales, K.S., Luco, N., Haller, K.M., Mueller, C.S., Shumway, A.M., 2018. Seismic Hazard, Risk, and Design for South America. Bulletin of the Seismological Society of America 108, 781-800. https://doi.org/10.1785/0120170002

Petrone, C., Rossetto, T., Baiguera, M., la Barra Bustamante, C.D., Ioannou, I., 2020. Fragility functions for a reinforced concrete structure subjected to earthquake and tsunami in sequence. Engineering Structures 205, 110120. https://doi.org/10.1016/j.engstruct.2019.110120

Pittore, M., 2015. A means of prioritizing data collection for efficient Geo-risk assessment. Annals of Geophysics, 58. https://doi.org/10.4401/ag6692

830 Pittore, M., Haas, M., Silva, V., 2020. Variable resolution probabilistic modeling of residential exposure and vulnerability for risk applications. Earthquake Spectra 36, 321-344. https://doi.org/10.1177/8755293020951582

Pittore, M., Haas, Megalooikonomou, 2018. Risk Oriented Bottom-up Modelling of building portfolios with faceted taxonomies.

PREDES, 2009. Diseño de escenario sobre el impacto de un sismo de gran magnitud en Lima Metropolitana y Callao". Reporte preparado para Instituto Nacional de Defensa Civil- INDECI. Agencia Suiza para el Desarrollo y la Cooperación COSUDE.

835 Pulido, N., Aguilar, Z., Tavera, H., Chlieh, M., Calderón, D., Sekiguchi, T., Nakai, S., Yamazaki, F., 2015. Scenario Source Models and Strong Ground Motion for Future Mega-earthquakes: Application to Lima, Central Peru. Bulletin of the Seismological Society of America $105,368-386$.

Salgado-Gálvez, MA., Ordaz, M., Singh, SK., Cardona, OD., Reinoso, E., Aguado, A., Zuloaga, D., Huerta, B., Bernal, G., 2018. Homogeneous and continous probabilistic seismic hazard model for Latin America and the Caribbean. Presented at the 16th European Conference on Earthquake Engineering, Thessaloniki, Greece, pp. 1-12.

Scheingraber, C., Käser, M., 2020. Spatial seismic hazard variation and adaptive sampling of portfolio location uncertainty in probabilistic seismic risk analysis. Natural Hazards and Earth System Sciences 20, 1903-1918. https://doi.org/10.5194/nhess-20-1903-2020

Scheingraber, C., Käser, M.A., 2019. The Impact of Portfolio Location Uncertainty on Probabilistic Seismic Risk Analysis. Risk Analysis 39, 695-712. https://doi.org/10.1111/risa.13176

845 Schelske, O., Sundermann, L., Hausmann, P., 2014. Mind the risk - A global ranking of cities under threat from natural disasters (No. Swiss Re, Report. No.1505715_13_en12/14).

Schiappapietra, E., Douglas, J., 2020. Modelling the spatial correlation of earthquake ground motion: Insights from the literature, data from the 2016-2017 Central Italy earthquake sequence and ground-motion simulations. Earth-Science Reviews 203, 103139. https://doi.org/10.1016/j.earscirev.2020.103139

850 Senouci, A., Bard, P.-Y., Beck, E., Farsi, M.N., Cartier, S., 2018. Mapping seismic vulnerability at urban scale: Discussion on relevant cartography representations and smoothing for urban planning purposes on the Oran case study. Soil Dynamics and Earthquake Engineering 115, 545-563. https://doi.org/10.1016/j.soildyn.2018.08.034

Silva, V., 2016. Critical Issues in Earthquake Scenario Loss Modeling. Journal of Earthquake Engineering 20, $1322-1341$. https://doi.org/10.1080/13632469.2016.1138172

855 Smith Mason, J., Retchless, D., Klippel, A., 2017. Domains of uncertainty visualization research: a visual summary approach. Cartography and Geographic Information Science 44, 296-309. https://doi.org/10.1080/15230406.2016.1154804

Song, J., De Risi, R., Goda, K., 2017. Influence of Flow Velocity on Tsunami Loss Estimation. Geosciences 7. 
https://doi.org/10.3390/geosciences7040114

Song, J., Goda, K., 2019. Influence of Elevation Data Resolution on Tsunami Loss Estimation and Insurance Rate-Making. Frontiers in Earth Science 7, 246. https://doi.org/10.3389/feart.2019.00246

Stafford, P.J., 2012. Evaluation of structural performance in the immediate aftermath of an earthquake: a case study of the 2011 Christchurch earthquake. International Journal of Forensic Engineering 1, 58-77. https://doi.org/10.1504/IJFE.2012.047447

Suppasri, A., Mas, E., Charvet, I., Gunasekera, R., Imai, K., Fukutani, Y., Abe, Y., Imamura, F., 2013. Building damage characteristics based on surveyed data and fragility curves of the 2011 Great East Japan tsunami. Natural Hazards 66, 319-341. https://doi.org/10.1007/s11069012-0487-8

Suppasri, A., Pakoksung, K., Charvet, I., Chua, C.T., Takahashi, N., Ornthammarath, T., Latcharote, P., Leelawat, N., Imamura, F., 2019. Loadresistance analysis: an alternative approach to tsunami damage assessment applied to the 2011 Great East Japan tsunami. Natural Hazards and Earth System Sciences 19, 1807-1822. https://doi.org/10.5194/nhess-19-1807-2019

Tang, L., Titov, V.V., Chamberlin, C.D., 2009. Development, testing, and applications of site-specific tsunami inundation models for real-time forecasting. Journal of Geophysical Research: Oceans 114. https://doi.org/10.1029/2009JC005476

Tappin, D.R., Grilli, S.T., Harris, J.C., Geller, R.J., Masterlark, T., Kirby, J.T., Shi, F., Ma, G., Thingbaijam, K.K.S., Mai, P.M., 2014. Did a submarine landslide contribute to the 2011 Tohoku tsunami? Marine Geology 357, $344-361$. https://doi.org/10.1016/j.margeo.2014.09.043

Triantafyllou, I., Novikova, T., Charalampakis, M., Fokaefs, A., Papadopoulos, G.A., 2019. Quantitative Tsunami Risk Assessment in Terms of Building Replacement Cost Based on Tsunami Modelling and GIS Methods: The Case of Crete Isl., Hellenic Arc. Pure and Applied Geophysics 176, 3207-3225. https://doi.org/10.1007/s00024-018-1984-9

Vamvatsikos, D., Panagopoulos, G., Kappos, A.J., Nigro, E., Rossetto, T., Lloyd, T.O., Stathopoulos, T., 2010. Structural Vulnerability Assessment under Natural Hazards: A review, in: Urban Habitat Constructions under Catastrophic Events, Chapter: 3-4. CRC Press. Editor: Mazzolani, F.M.

880 Viard, T., Caumon, G., Lévy, B., 2011. Adjacent versus coincident representations of geospatial uncertainty: Which promote better decisions? Computers \& Geosciences 37, 511-520. https://doi.org/10.1016/j.cageo.2010.08.004

Villar-Vega, M., Silva, V., Crowley, H., Yepes, C., Tarque, N., Acevedo, A.B., Hube, M.A., Gustavo, C.D., María, H.S., 2017. Development of a Fragility Model for the Residential Building Stock in South America. Earthquake Spectra 33, 581-604. https://doi.org/10.1193/010716EQS005M

Villegas-Lanza, J.C., Chlieh, M., Cavalié, O., Tavera, H., Baby, P., Chire-Chira, J., Nocquet, J.-M., 2016. Active tectonics of Peru: Heterogeneous interseismic coupling along the Nazca megathrust, rigid motion of the Peruvian Sliver, and Subandean shortening accommodation. Journal of Geophysical Research: Solid Earth 121, 7371-7394. https://doi.org/10.1002/2016JB013080

Ward, P.J., Blauhut, V., Bloemendaal, N., Daniell, J.E., de Ruiter, M.C., Duncan, M.J., Emberson, R., Jenkins, S.F., Kirschbaum, D., Kunz, M., Mohr, S., Muis, S., Riddell, G.A., Schäfer, A., Stanley, T., Veldkamp, T.I.E., Winsemius, H.C., 2020. Review article: Natural hazard risk assessments at the global scale. Natural Hazards and Earth System Sciences 20, 1069-1096. https://doi.org/10.5194/nhess-20$1069-2020$

Weatherill, G.A., Silva, V., Crowley, H., Bazzurro, P., 2015. Exploring the impact of spatial correlations and uncertainties for portfolio analysis in probabilistic seismic loss estimation. Bulletin of Earthquake Engineering 13, 957-981. https://doi.org/10.1007/s10518-015-9730-5

Wronna, M., Omira, R., Baptista, M.A., 2015. Deterministic approach for multiple-source tsunami hazard assessment for Sines, Portugal. Natural Hazards and Earth System Sciences 15, 2557-2568. https://doi.org/10.5194/nhess-15-2557-2015

Yepes-Estrada, C., Silva, V., Valcárcel, J., Acevedo, A.B., Tarque, N., Hube, M.A., Coronel, G., María, H.S., 2017. Modeling the Residential Building Inventory in South America for Seismic Risk Assessment. Earthquake Spectra 33, $299-322$. https://doi.org/10.1193/101915eqs155dp

Yilmaz, C., Silva, V., Weatherill, G., 2021. Probabilistic framework for regional loss assessment due to earthquake-induced liquefaction including epistemic uncertainty. Soil Dynamics and Earthquake Engineering 141, 106493. https://doi.org/10.1016/j.soildyn.2020.106493

Zuccaro, G., De Gregorio, D., Leone, M.F., 2018. Theoretical model for cascading effects analyses. International Journal of Disaster Risk Reduction 30, 199-215. https://doi.org/10.1016/j.ijdrr.2018.04.019 